\title{
On the Asset Allocation of a Default Pension Fund
}

\author{
Magnus Dahlquist Ofer Setty Roine Vestman*
}

November 5, 2016

\begin{abstract}
We characterize the optimal default fund in a defined contribution (DC) pension plan. Using detailed data on individuals' holdings inside and outside the pension system, we find substantial heterogeneity within and between passive and active investors in terms of labor income, financial wealth, and stock market participation. We build a life-cycle consumption-savings model with a DC pension account and an opt-out/default choice. The model produces realistic investor heterogeneity. We examine the optimal default asset allocation, which implies a welfare gain of $1.5 \%$ over a common age-based allocation. Most of the gain is attainable with a simple rule of thumb.
\end{abstract}

JEL classification: D91, E21, G11, H55.

Keywords: Age-based investing, default fund, life-cycle model, pension-plan design.

*The first version of this paper was circulated under the title "On the Design of a Default Pension Fund." We have benefited from the comments of João Cocco, Pierre Collin-Dufresne, Anthony Cookson, Frank de Jong, Francisco Gomes, Michael Haliassos, Harrison Hong, John Hassler, Seoyoung Kim, Samuli Knüpfer, Per Krusell, Deborah Lucas, Robert Merton, Alexander Michaelides, Kim Peijnenburg, Paolo Sodini, Carsten Sørensen, Ole Settergren, Annika Sundén, and participants at various seminars and conferences. The research leading to these results received funding from the People Programme (Marie Curie Actions) of the European Union's Seventh Framework Programme (FP7), 2010-2013, under REA grant agreement number 276770. Financial support from the NBER Household Finance working group is gratefully acknowledged. Dahlquist: Stockholm School of Economics and CEPR; e-mail: magnus.dahlquist@hhs.se. Setty: Tel Aviv University; e-mail: ofer.setty@gmail.com. Vestman: Stockholm University; email: roine.vestman@ne.su.se. 


\section{Introduction}

The worldwide shift from defined benefit (DB) to defined contribution (DC) pension plans challenges pension investors, who have been given greater responsibility to choose their contribution rates and manage their savings. Many investors seem uninterested, display inertia (Madrian and Shea, 2001), or lack financial literacy (Lusardi and Mitchell, 2014), and end up in the default option. Consequently, the design of the default option in a pension plan is a powerful tool for improving investment outcomes $1^{1}$

This paper studies one important aspect of the design of the default option: the optimal asset allocation. The asset allocation aspect is particularly suitable for designing wise default funds as the optimal allocation decision requires knowledge about asset classes and financial literacy while knowledge about the optimal contribution rate may be intrinsic to the individual (Carrol et al., 2009; Choi et al., 2010). We make both an empirical and a theoretical contribution to this literature. We begin by constructing a dataset of Swedish investors' detailed asset holdings inside and outside the pension system ${ }^{2}$ We find that remaining in the default fund or being passive for a long time after an initial opt-out decision is a strong indicator of not having any equity exposure outside the pension system. These default and passive investors (henceforth simply referred to as passive investors) have a $27 \%$ lower stock market participation rate outside the pension system than do active investors (a gap of 16 percentage points), one third of the difference being unexplained by observable characteristics such as labor income, financial wealth, and education. Overall, passive investors can be characterized as less sophisticated. Moreover, there is a great deal of heterogeneity among

\footnotetext{
${ }^{1}$ Studies have examined the design of the enrollment features (Carrol et al., 2009), contribution rates (Madrian and Shea, 2001; Choi et al., 2003), choice menus (Cronqvist and Thaler, 2004), and equity exposures within pension plans (Benartzi and Thaler, 2001; Huberman and Jiang, 2006). Benartzi and Thaler (2007) have reviewed heuristics and biases in retirement savings behavior. More recently, Chetty et al. (2014) document inertia among $85 \%$ of Danish pension investors with respect to their contribution rates, Poterba (2014) discusses the savings rates required in order to obtain warranted replacement rates, and Sialm et al. (2015) argue that sponsors of DC plans adjust the options of the plan to overcome investor inertia.

${ }^{2}$ Calvet et al. $(2007,2009)$ have made use of the data on asset holdings outside the pension system. To the best of our knowledge, we are the first to combine these register-based data with information about savings inside the pension system. Bergstresser and Poterba (2004) and Christelis et al. (2011) use survey data when studying equity exposure and the location choice between taxable and tax-deferred accounts.
} 
passive investors. Passive investors who participate in the stock market have financial wealth equal to 1.4 years of labor income, while passive investors who do not participate have financial wealth equal to only five months of labor income. Similarly, participating passive investors have 4.3 times as much financial wealth as do non-participating passive investors. These basic facts make it reasonable to question the ability of a one-size-fits-all design of the default fund to meet all passive investors' needs.

We then set up a model to study the decision of whether to be active or not and to study the optimal asset allocation of the default fund for passive investors. Our model belongs to the class of life-cycle portfolio choice models with risky labor income (see, e.g., Cocco et al., 2005; Gomes and Michaelides, 2005), which we extend to include a pension system. The pension system has a DC pension account so that illiquid savings inside the pension system coexist with liquid savings outside the pension system. The decision to be active or passive in the DC pension account and the decision whether to participate in the stock market outside of the pension system are endogenous but subject to costs. We justify a dispersion in costs with heterogeneity in financial literacy and financial sophistication (e.g., experience of making investment decisions and various costs associated with investing). While an endogenous decision for stock market participation is standard, our model is the first to endogenously determine the passive pension investors. Supported by our empirical work, the model matches the stock market participation rates among passive and active pension investors. The source of the 16 percentage points gap is driven partly by the two costs being modestly positively correlated. Our rich model also generates cross-sectional heterogeneity in labor income and financial wealth (in line with the data).

We use the model to study the optimal asset allocation for default investors with different individual characteristics and for investors who have experienced different stock market returns. The model provides a normative suggestion on what the asset allocation should be. We find substantial heterogeneity in the optimal allocation to equity in the DC pension account. The year before retirement, the highest decile has an optimal equity share above $39 \%$, while the lowest decile has an optimal equity share below $9 \%$. We also find that the optimal equity share varies substantially with the stock market's past performance. The 
year before retirement, the optimal equity share for the average investor is above $34 \%$ with a $10 \%$ probability and below $20 \%$ with a $10 \%$ probability. The reason is that the optimal asset allocation involves active rebalancing.

In terms of welfare gains, a full customization of the default fund implies individual improvements in the range of $0.9 \%$ to $2.9 \%$ of consumption equivalent during the retirement phase, with a mean gain of $1.5 \%$. Importantly, changes to the default fund's asset allocation are Pareto improving. There are only winners and no losers seen from an ex ante perspective, unlike for instance a redistributive tax reform. This suggests that efforts spent to create wise default asset allocations are well spent.

That passive and active investors are endogenously determined in the model is important. As in Carroll et al. (2009), passive investors endogenously adapt to changes in the default design. We examine how the share of passive investors change as the degree of customization of the default to individual circumstances increases. Starting from a common age-based investing rule (100 minus one's age being the percentage allocated to equity), we find that a simple rule of thumb that conditions on the age, the DC account balance, and stock market participation status of the investor reduces the share of active investors (who opt out) by $40 \%$. Furthermore, $58 \%$ of the total welfare gain associated with the implementation of the true optimal design is achieved by implementing our proposed rule of thumb. Moreover, we find that the rule can be robustly estimated across different (endogenously created) samples of default investors. This suggests that the rule is flexible enough to accommodate default investors that have arisen from varying institutional settings and initial designs.

These results are encouraging for a designer of the default option in a DC pension plan (e.g., a plan sponsor such as an employer or the government) as a large share of the total welfare gain is achievable through simple mass-customization based on few observable characteristics. We know of no previous rule of thumb derived from the optimal default design within the class of life-cycle portfolio choice models. At a conceptual level, the proposed rule of thumb only diverges in two ways from standard age-based investing or inter-temporal hedging (Merton, 1971). First, the DC account balance in itself is a useful instrument guiding the asset allocation decision. If the account balance is low e.g. due to poor past equity 
returns, more equity risk can be assumed, while the reverse is the case if the account balance is high due to good past equity returns. We find this result particularly useful because the account balance itself is readily available information, making the rule cost effective to implement (see Bodie et al., 2009, for a discussion of the costs of individualized allocations). Second, we find that the stock market participation status outside the pension system provides considerable information about the investor. On average, non-participants should have a 20-percentage-point higher equity share relative to that of participants. The intuition is simply that non-participants have no access to stocks outside of the pension system and therefore the exposure within the default fund is of great importance.

Importantly, our results hold if investors' portfolio choices outside the pension system are subject to frictions or investment mistakes (Choi et al., 2009; Card and Randsom, 2011; Chetty et al. 2014; Campbell, 2016), if the equity risk premium is low, if equity returns are left-skewed, or if the baseline share of passive investors is small. In particular, the welfare gain, the fraction of it that can be achieved by using the rule of thumb, and the changes in the fraction of investors who opt out, are all similar to those in the main analysis.

Our work relates to that of Gomes et al. (2009), Campanale et al. (2014), and Dammon et al. (2004). Gomes et al. (2009) study the effects of tax-deferred retirement accounts and find the largest effects on savings rates relative to a non-tax environment for investors with high savings rates. Campanale et al. (2014) investigate how stock market illiquidity affects a portfolio choice model's ability to replicate the distribution of stock holdings over the life cycle and the wealth distribution. Dammon, Spatt, and Zhang (2004) study the location decision for stocks and bonds in liquid taxable and illiquid tax-deferrable accounts.

Our work also relates to that of Lucas and Zeldes (2009), who deal with the investment decisions of pension plans in the aggregate. However, our model considers individual outcomes beyond aggregate ones at the pension plan level. In this sense, Shiller's (2006) evaluation of the life-cycle personal accounts for Social Security is closer to our study. Our focus on investor heterogeneity is complementary to the work of Poterba et al. (2007), who simulate individuals' pension benefits in DB and DC plans and report distributions across individuals. 
The paper proceeds as follows. Section 2 provides an overview of the Swedish pension system. Section 3 describes our data. Section 4 empirically analyzes individuals' portfolio choices inside and outside the pension system and how they are related. Section 5 presents our life-cycle model and its calibration. Section 6 analyzes the optimal design of the default pension fund. It also analyzes gradual customization and considers various robustness tests. Finally, Section 7 concludes.

\section{The Swedish pension system}

The Swedish pension system rests on three pillars: public pensions, occupational pensions, and private savings. Below, we describe the public and occupational pensions.

The public pension system was reformed in $2000 \cdot 3$ It has two major components referred to as the income-based pension and the premium pension. A means-tested benefit provides a minimum guaranteed pension.

The contribution to the income-based pension is $16 \%$ of an individual's income, though the income is capped (in 2016 the cap is SEK 444,750, or approximately USD 53,300). 4 The return on the contribution equals the growth rate of aggregate labor income measured by an official "income index." Effectively, the return on the income-based pension is similar to that of a real bond. The income-based pension is notional in that it is not reserved for the individual but is instead used to fund current pension payments as in a traditional pay-asyou-go system. The notional income-based pension is also DC, but to avoid confusion we simply refer to it as the notional pension.

The contribution to the premium pension is $2.5 \%$ of an individual's income (capped as above). Unlike the income-based pension, the premium pension is a fully funded DC account used to finance the individual's future pension. Individuals can choose to actively

\footnotetext{
${ }^{3}$ Individuals born between 1938 and 1954 are enrolled in a mix of the old and new pension systems, while individuals born after 1954 are enrolled entirely in the new system.

${ }^{4}$ In the beginning of 2016 the SEK/USD exchange was 8.35. During our sample period, the exchange rate has fluctuated between six and ten SEK per USD. We often report numbers from 2007 when the exchange rate at the end of the year was 6.47. We henceforth report numbers in SEK.
} 
allocate their contributions to up to five mutual funds from a menu of several hundred. The premium pension makes it possible for individuals to gain equity exposure. Indeed, most of the investments in the system have been in equity funds (see, e.g., Dahlquist et al., 2016). A government agency manages a default fund for individuals who are passive and do not make an investment choice. Up to 2010, the default fund invested mainly in stocks but also in bonds and alternatives. In 2010, the default fund became a life-cycle fund. At the time of retirement, the savings in the income-based pension and the premium pension are transformed into actuarially fair life-long annuities.

In addition to public pensions, approximately $90 \%$ of the Swedish workforce is entitled to occupational pensions. Agreements between labor unions and employer organizations are broad and inclusive and have gradually been harmonized across educational and occupational groups. For individuals born after 1980, the rules are fairly homogenous, regardless of education and occupation. The contribution is $4.5 \%$ of an individual's income up to the cap in the public pension system and greater for the part of the income that exceeds that cap, in order to compensate for the cap in the public pension and to achieve a similar replacement rate even for high-income individuals. These contributions go into a designated individual DC account. While the occupational pension is somewhat more complex and tailored to specific needs, it shares many features with the premium pension. Specifically, it is an individual DC account and there is a menu of mutual funds to choose from. The plan sponsor decides on the default fund.

Next we discuss our data on individuals' savings inside and outside the pension system.

\section{Data}

We tailor a registry-based dataset to our specific needs. This dataset's foundation is a representative panel dataset for Sweden, LINDA (Longitudinal Individual Data). LINDA covers more than 300,000 households and is compiled by Statistics Sweden. We use eight waves between 2000 and 2007 and consider socioeconomic information such as age, education, and labor income. Our sample period is determined by the launch of the new pension system 
in 2000 and by the availability of detailed financial wealth data (described below) up to 2007. The Online Appendix contains further information on LINDA. We match LINDA with data from two additional sources.

We first add data from the Swedish Tax Agency (through Statistics Sweden) which cover each individual's non-pension financial wealth. It is a registry-based source of financial holdings outside the public pension system. Specifically, the tax reporting allows us to compute the value of the holdings of all bonds, stocks, and mutual funds that an individual holds at the end of each year. There are three exceptions to these detailed tax reports. The first exception is the holdings of financial assets within private pension accounts, for which we observe only additions and withdrawals. The second exception is that bank accounts with small balances are missing. To match the aggregate these missing values are imputed. The third exception is the so-called capital insurance accounts, for which we observe the account balances but not the detailed holdings.5 There is also a tax on real estate, which allows us to accurately measure the value of owner-occupied single-family houses and second homes. Apartment values are also available, though they are less accurately measured.

We also add data from the Swedish Pensions Agency which cover pension savings. We have information on individuals' entry into the pension system and on their mutual fund holdings in their premium pension accounts at the end of each year. Unfortunately, it is impossible to match these data with occupational pension accounts because these accounts are administered by private entities. Moreover, individuals' holdings in occupational pension plans are not covered by the tax-based dataset described above. However, we know the typical contribution rates in occupational pension plans and the typical allocation of these plans to equities and bonds. In our model, we will assume that the typical contribution rate and allocation in occupational pension plans apply to all enrolled individuals.

In previous studies, the tax-based holdings information and records from the Swedish Pensions Agency have been used separately. Calvet et al. (2007, 2009), Vestman (2015), and

\footnotetext{
${ }^{5}$ Capital insurance accounts are savings vehicles that are not subject to the regular capital gains and dividend income taxes, but are instead taxed at a flat rate on the account balance. According to Calvet et al. (2007), these accounts accounted for $16 \%$ of aggregate financial wealth in 2002.
} 
Koijen et al. (2015) use non-pension financial wealth to answer questions related to investors' diversification, portfolio rebalancing, housing and stock market participation, and consumption expenses. Dahlquist et al. (2016) use information from the Swedish Pensions Agency to analyze the activity and performance of pension investors. To the best of our knowledge, we are the first to combine comprehensive and high-quality panel data on individuals' investments inside and outside the pension system.

\section{Empirical analysis}

\subsection{Sample restrictions}

We begin with all individuals in the 2007 wave of LINDA and match them with the Swedish Pensions Agency's records of DC account holdings at the end of every year between 2000 and 2007. There are 430,216 individuals covered in both datasets. We then impose four sample restrictions. We exclude individuals for whom we lack portfolio information at the end of each year since they entered the premium pension system. To better match the model to data, we also exclude the richest percentile in terms of net worth. We also exclude individuals below age 25 as they do not fully qualify for occupational pension plans. Finally, we exclude individuals for whom we lack educational information; this applies mainly to recent immigrants and the very old. Our final sample consists of 301,632 individuals.

\subsection{Passive and active pension investors}

We classify all individual investors as either passive or active. We base the classification on the activity in the DC account between 2000 and 2007. Passive investors are either investors who have had their premium pension in the default fund since entering the pension system or investors that opted out of the default fund when entering the pension system but since then have never changed their allocations.

The default investors have clearly been passive. Our classification of the initially active investors as passive is based on three arguments. First, at the time of the launch there was 
strong encouragement to actively choose a portfolio of one's own. This was done via massive advertising campaigns from the government and money management firms (see Cronqvist and Thaler, 2004, who characterize the launch of the plan as "pro choice"). However, that many individuals who opted out never made any subsequent allocation changes suggests that they would have been in the default fund if not so strongly encouraged to opt out. Second, Dahlquist et al. (2016) document that initially active investors on average have had worse returns than active and default investors, which refutes the idea that the reason for their passivity is complacency. Third, our classification is consistent with the substantial increase of default investors in the years after the launch. For example, among 25 year-old individuals the fraction of new investors that stayed in the default increased from $27 \%$ in 2000 to $66 \%$ in 2001, and thereafter increased steadily to $92 \%$ in 2007.

Active investors have, after entering the pension system, opted out and made at least one change to their allocations. Note that our classification based on activity relies on the panel dimension of the data. Previous analysis of the choice between taxable and tax-deferred accounts has relied on cross-sectional data (see, e.g., Christelis et al., 2011).

\subsection{Summary statistics}

Table 1 reports the averages of key variables in 2007. The first column reports the values for all investors and the remaining two columns report the values for passive and active investors. Passive investors account for $60.5 \%$ of all investors while active investors account for $39.5 \%$. Out of the passive investors, $51.8 \%$ are default investors and the remaining $48.2 \%$ opted out of the default fund when entering the pension system but since then have never changed their allocations.

The average investor is 47 years old and there is no substantial difference in age between passive and active investors. The average labor income of a passive investor is SEK 224,526,

or only $79 \%$ of the average labor income of active investors. In untabulated results, we find that this ratio is fairly stable over the life cycle. Hence, the difference in labor income between passive and active investors is not attributable to age differences, but is likely an artifact of 
other differences (e.g., educational differences, as discussed below). Similarly, there is also a substantial difference in financial wealth (i.e., liquid savings not tied to pension accounts). The financial wealth of the average passive investor relative to that of the average active investor is only $74 \%$. Taken together, this means that the pension savings become relatively more important to passive investors.

The table also reports the stock market exposure outside the pension system. We define stock market participation as direct investments in stocks or investments in equity mutual funds. The stock market participation is $45.5 \%$ for passive investors and $61.9 \%$ for active investors. That is, passive investors have 16.4 percentage points (or 26.5\%) lower stock market participation rate than active investors. The lower participation of passive investors also shows up in equity shares. The average equity share is $19.6 \%$ for passive investors and $29.0 \%$ for active investors. However, conditioning on stock market participation, the passive and active investors have similar equity shares (43.2\% and $46.9 \%$, respectively).

There are also large differences in real estate ownership. The main reason for this difference is that the real estate ownership rate among passive investors is $65.2 \%$, much lower than the $79.3 \%$ among active investors. The differences in financial and real estate wealth are captured in net worth, which is the total wealth minus total liabilities. The differences in total wealth result from differences in both financial wealth and real estate wealth.

Finally, passive and active investors also differ in education. Though the fraction of high school graduates is about the same (53.9\% for passive investors and $55.1 \%$ for active investors), the fraction of investors with a college degree is five percentage points lower among passive investors than among active investors (26.7\% versus $32.0 \%)$. Instead, passive investors are much more likely than active investors to have finished only elementary school (18.4\% versus $11.6 \%)$.

\subsection{Activity and stock market participation}

We next turn to a more formal comparison of investment behavior inside and outside the pension system. Specifically, we study how activity inside the pension system relates to stock 
market participation outside the pension system. We begin by running two main regressions:

$$
\begin{aligned}
D\left(\text { Activity }_{i}=1\right) & =\alpha^{\prime} X_{i}+\varepsilon_{i}^{\mathrm{A}}, \\
D\left(\text { Participation }_{i}=1\right) & =\beta^{\prime} X_{i}+\varepsilon_{i}^{\mathrm{P}},
\end{aligned}
$$

where $D\left(\right.$ Activity $\left._{i}=1\right)$ is a dummy variable that takes a value of one if the individual is active inside the pension system, $D\left(\right.$ Participation $\left._{i}=1\right)$ is a dummy variable that takes a value of one if the individual holds stocks directly or equity funds outside the pension system, $X_{i}$ is a vector of individual characteristics, and $\varepsilon_{i}^{\mathrm{A}}$ and $\varepsilon_{i}^{\mathrm{P}}$ are error terms. As the classification of activity refers to the 2000-2007 period, we restrict ourselves to consider activity and participation at the end of 2007. Initially, we let activity and participation be linear in the individual characteristics. However, later we also consider piecewise linear splines for the continuous characteristics. The characteristics are largely chosen to be consistent with a structural life-cycle model of portfolio choice, similar to the model we set up in the next section. Hence, we include age, labor income, and financial wealth as individual characteristics; we also consider a real estate dummy, educational dummies, and geographical dummies.

We then run a complementary regression:

$$
\hat{\varepsilon}_{i}^{\mathrm{P}}=\gamma \hat{\varepsilon}_{i}^{\mathrm{A}}+\varepsilon_{i}
$$

where $\hat{\varepsilon}_{i}^{\mathrm{A}}$ and $\hat{\varepsilon}_{i}^{\mathrm{P}}$ are the residuals from regressions $(1)$ and (2), and $\varepsilon_{i}$ is an error term. This residual regression helps us understand the commonality of endogenous activity inside the pension system and endogenous stock market participation outside the pension system, after controlling for individual characteristics in $X_{i}$. We emphasize that we do not make a causal interpretation (i.e., that activity would cause participation). The regression simply captures the correlation between activity and participation after controlling for age, labor income, financial wealth, etc.

Panel A in Table 2 reports the results from the main regressions (1) and (2). (Note that in the regressions age is scaled down by 100, and labor income and financial wealth are scaled 
down by 1,000,000.) Specifications I and III serve as benchmarks and refer to the linear specifications. Activity and participation are both positively related to age, labor income, and financial wealth. The estimated effects of being ten years older is a 0.4 percentagepoint-higher activity rate and a 2.2 percentage-point-higher participation rate. The effects of SEK 100,000 more in labor income are similar for activity and participation (2.2 and 1.7 percentage points higher), while the effects of SEK 100,000 more in financial wealth is lower for activity than for participation (0.5 and 2.8 percentage points higher). In untabulated results, we have also considered specifications with industry and occupational dummies. The results are very similar.

The estimates above can be compared with the estimate in the residual regression (3), reported in Panel B. The results indicate that after controlling for individual characteristics, there is a strong positive relationship between activity in the pension system and stock market participation. Being an active investor in the pension system increases the likelihood of having equity exposure outside the pension system by 10.1 percentage points. This effect can in turn be compared with the 16.4 percentage-point difference in the unconditional participation rate between passive and active investors. That is, including a rich set of controls reduces the participation rate gap by 6.3 percentage points, but it remains substantial.

Specifications II and IV let age, labor income, and financial wealth enter as piecewise linear splines. Even with these richer specifications, there is still a strong positive relationship between activity and stock market participation. An active investor in the pension system is 6.0-percentage-points more likely to participate in the stock market outside the pension system. Hence, our results suggest that $37 \%$ of the gap is driven by differences in unobservable characteristics. One such unobservable characteristic could be the experience of making investment decisions.

The bottom-line finding of our regressions is that activity in the pension system is strongly associated with equity exposure outside the pension system. Even when controlling for individual characteristics that correspond to the state variables of a standard life-cycle portfolio choice model, the gap in stock market participation between passive and active investors is substantial. These findings have implications for the design of an optimal default fund. In 
addition, the findings underscore the importance of modeling limited stock market participation outside the pension system. We will design and calibrate our model to capture both the choice of being active in the pension system and the choice of participating in the stock market outside the pension system.

\subsection{Heterogeneity among passive investors}

In this section we demonstrate that there is considerable heterogeneity among passive investors. Understanding how these investors differ from one another is important for the design of a default fund. Table 3 presents the distributions of variables for passive investors. Panel A shows that passive investors exist in all age categories and differ greatly in labor income, financial wealth, and equity exposure. Regarding the inequality in labor income, $25 \%$ of passive investors earn less than SEK 99,911 whereas 25\% earn more than SEK 303,797. The inequality in financial wealth is also great: 25\% have less than SEK 17,116 in financial wealth whereas $25 \%$ have SEK 218,505 or more. This inequality applies to equity exposure as well, most passive investors having no equity exposure outside the pension system, whereas $10 \%$ have at least $63.4 \%$ of their financial wealth allocated to equities.

In Panels $\mathrm{B}$ and $\mathrm{C}$, passive investors are split into stock market participants and nonparticipants. While participants and non-participants differ little in age, they differ somewhat in labor income and a great deal in financial wealth. The median non-participant earns $18 \%$ less than does the median participant. Furthermore, the median non-participant has

just $15 \%$ of the financial wealth of the median participant. Only $10 \%$ of participants have less financial wealth than does the median non-participant. Finally, financial wealth can be contrasted to labor income. Stock market participants have financial wealth worth 1.4 years of labor income, while non-participants have financial wealth worth just five months of labor income. As participants have higher labor income, the average participating passive investor has 4.3 times as much financial wealth as does the average non-participating passive investor.

The takeaway is that there is considerable heterogeneity even among passive fund in- 
vestors. Specifically, stock market participation serves the function of an indicator variable, most participants being richer in terms of both labor income and financial wealth. These basic facts make it reasonable to question the ability of a one-size-fits-all design of the default fund to meet all investors' needs. This suggests that it may be beneficial to carefully design the default fund to suit each investor's specific situation rather than imposing one allocation on all.

\section{Model}

Following the empirical analysis, we set up a life-cycle model for an investor to study the decision of whether or not to be active and to examine the optimal asset allocation of the default fund for passive investors. The model builds on the work of Viceira (2001), Cocco et al. (2005), and Gomes and Michaelides (2005) and includes risky labor income, a consumption-savings choice, and a portfolio choice. We extend the standard model with a pension system in which individuals save in illiquid pension accounts, from which their pension is received as annuities. Importantly, we also extend the model with an endogenous decision whether to remain in the default pension fund or opt out. Next we describe the model's building blocks.

\subsection{Demographics}

We follow individuals from age 25 until the end of their lives. The end of life occurs at the latest at age 100, but could occur before as individuals face an age-specific survival rate, $\phi_{t}$. The life cycle is split into a working phase and a retirement phase. From the ages of 25 to 64 years, individuals work and receive labor income exogenously. They retire at age 65 . 


\section{$5.2 \quad$ Preferences}

The individuals have Epstein and Zin (1989) preferences over a single consumption good. At age $t$, each individual maximizes the following:

$$
\begin{aligned}
U_{t} & =\left(c_{t}^{1-\rho}+\beta \phi_{t} E_{t}\left[U_{t+1}^{1-\gamma}\right]^{\frac{1-\rho}{1-\gamma}}\right)^{\frac{1}{1-\rho}}, \\
U_{T} & =c_{T},
\end{aligned}
$$

where $\beta$ is the discount factor, $\psi=1 / \rho$ is the elasticity of intertemporal substitution, $\gamma$ is the coefficient of relative risk aversion, and $t=25,26, \ldots, T$ with $T=100$. For notational convenience, we define the operator $\mathcal{R}_{t}\left(U_{t+1}\right) \equiv E_{t}\left[U_{t+1}^{1-\gamma}\right]^{\frac{1}{1-\gamma}}$.

\subsection{Labor income}

Let $Y_{i t}$ denote the labor income of employed individual $i$ at age $t$. During the working phase (up to age 64), the individual faces a labor income process with a life-cycle trend and permanent income shocks:

$$
\begin{aligned}
& y_{i t}=g_{t}+z_{i t}, \\
& z_{i t}=z_{i t-1}+\eta_{i t}+\theta \varepsilon_{t},
\end{aligned}
$$

where $y_{i t}=\ln \left(Y_{i t}\right)$. The first component, $g_{t}$, is a hump-shaped life-cycle trend. The second component, $z_{i t}$, is the permanent labor income component. It has an idiosyncratic shock, $\eta_{i t}$, which is distributed $\mathrm{N}\left(-\sigma_{\eta}^{2} / 2, \sigma_{\eta}^{2}\right)$, and an aggregate shock, $\varepsilon_{t}$, which is distributed $\mathrm{N}\left(-\sigma_{\varepsilon}^{2} / 2, \sigma_{\varepsilon}^{2}\right)$. The aggregate shock also affects the stock return, and $\theta$ determines the contemporaneous correlation between the labor income and the stock return. We allow for heterogeneity in income at age 25 by letting the initial persistent shock, $z_{i 25}$, be distributed $\mathrm{N}\left(-\sigma_{z}^{2} / 2, \sigma_{z}^{2}\right)$.

During the retirement phase (from age 65 and onwards), the individual has no labor 
income $5^{6}$ Pension is often modeled as a deterministic replacement rate relative to the labor income just before retirement. $]^{7}$ However, in our model, the replacement rate is endogenously determined. Apart from own savings in (liquid) financial saving, the individual relies entirely on annuity payments from pension accounts. Later we discuss these accounts in detail.

\subsection{Investor heterogeneity}

The decision to opt out from the default pension fund as well as the decision to participate in the stock market outside the pension system are endogenous. Both of these decisions are surrounded by frictions. To opt out, a one-time cost $\kappa_{i}^{\mathrm{DC}}$ must be paid; to enter the stock market, a one-time cost $\kappa_{i}$ must be paid. A new feature of our model is that we allow for different magnitudes of these costs for different investors. The support of each cost's crosssectional distribution as well as the correlation between them are set to match the shares of active and passive non-participants, and the shares of active and passive participants in the data. The joint distribution of $\kappa_{i}^{\mathrm{DC}}$ and $\kappa_{i}$ is non-parametric. The calibration section describes the process for determining the joint distribution. While the costs are known to each investor, we will in some analysis treat the costs as unobserved for a default fund designer.

One-time costs of our kind are common in portfolio-choice models (see, e.g., Alan, 2006; Gomes and Michaelides, 2005, 2008). We allow for a full cross-sectional joint distribution of costs over the two endogenous decisions. We justify the dispersion in costs with reference to the documented heterogeneity in financial literacy and financial sophistication (see Lusardi and Mitchell, 2014, for an overview). Moreover, by introducing a dispersion in the cost of participating in the stock market, we can better capture the life-cycle participation profile in the data. 8

\footnotetext{
${ }^{6}$ Hence, the retirement decision is not endogenous as in French and Jones (2011). More generally, we do not consider endogenous labor supply decisions as in Bodie et al. (1992) and Gomes et al. (2008).

${ }^{7}$ One exception is that of Cocco and Lopes (2011), who model the preferred DB or DC pension plan for different investors.

${ }^{8}$ Fagereng et al. (2015) present an alternative set-up to account for the empirical life-cycle profiles on portfolio choice. Their model involves a per-period cost and a probability of a large loss on equity investments. We consider a probability of a large return loss in the robustness analysis.
} 


\subsection{Opting out and participating in the stock market}

The decision to opt-out from the default pension fund is made at age 25 and is associated with

a binary state variable $I_{i}^{\mathrm{DC}}$. This is consistent with the high degree of persistent inactivity among pension investors ever since the launch in 2000. Since the opt-out choice is made at age 25 there is a trivial law of motion for $I_{i}^{\mathrm{DC}}$ and it is denoted without a time subscript.

The decision to enter the stock market can be made at any stage of the life cycle. Stock market participation is associated with a persistent binary state variable $I_{i t}$ that tracks the current status at $t$. The law of motion for $I_{i t}$ is:

$$
I_{i t}=\left\{\begin{array}{l}
1 \text { if } I_{i t-1}=1 \text { or } \alpha_{i t}>0 \\
0 \text { otherwise }
\end{array}\right.
$$

where $\alpha_{i t}$ is the fraction of financial wealth invested in the stock market. The cost associated with stock market entry then becomes $\kappa_{i}\left(I_{i t}-I_{i t-1}\right)$.

\subsection{Asset returns}

The gross return on the stock market, $R_{t+1}$, follows a log-normal process:

$$
\ln \left(R_{t+1}\right)=\ln \left(R_{f}\right)+\mu+\varepsilon_{t+1}
$$

where $R_{f}$ is the gross return on a risk-free bond and $\mu$ is the equity premium. Recall that the shock, $\varepsilon_{t}$, is distributed $\mathrm{N}\left(-\sigma_{\varepsilon}^{2} / 2, \sigma_{\varepsilon}^{2}\right)$, so $E_{t}\left(R_{t+1}-R_{f}\right)=\mu$. Also recall that $\varepsilon_{t}$ affects labor income in (7), and that the correlation between stock returns and labor income is governed by the parameter $\theta$.

\subsection{Three accounts for financial wealth}

Each individual has three financial savings accounts: (i) a liquid account outside the pension system (which we simply refer to as financial wealth), (ii) a fully-funded DC account in the pension system, and (iii) a notional account belonging to the pension system. The notional 
account, which provides the basis for the pension, is income based and evolves at the rate of the risk-free bond. The DC account is also income based but the investor can choose how to allocate between bonds and stocks; it corresponds to the default fund we wish to design.

The account outside the pension system is accessible at any time. Each individual chooses freely how much to save and withdraw from it. In contrast, the contributions to the pension accounts during the working phase are determined by the pension policy (rather than by the individual) and are accessible only in the form of annuities during the retirement phase. Importantly, the two pension accounts include insurance against longevity risk.

\section{Financial wealth}

The individual starts the first year of the working phase with financial wealth, $A_{i 25}$, outside the pension system. The log of initial financial wealth is distributed $\mathrm{N}\left(\mu_{A}-\sigma_{A}^{2} / 2, \sigma_{A}^{2}\right)$. In each subsequent year, the individual can freely access the financial wealth, make deposits, and choose the fraction to be invested in risk-free bonds and in the stock market. However, the individual cannot borrow:

$$
A_{i t} \geq 0
$$

and the equity share is restricted to be between zero and one:

$$
\alpha_{i t} \in[0,1]
$$

Taken together, (10) and (11) imply that individuals cannot borrow at the risk-free rate and that they cannot short the stock market or take leveraged positions in it.

The individual's cash on hand (i.e., the sum of financial wealth and labor income) develops according to:

$$
X_{i t+1}=A_{i t}\left(R_{f}+\alpha_{i t}\left(R_{t+1}-R_{f}\right)\right)+Y_{i t+1}
$$

Supported by the analysis in Fischer et al. (2013), we do not model taxes on capital gains. 


\section{DC account}

Inside the pension system, each individual has a DC account with a balance equal to $A_{i t}^{\mathrm{DC}}$. During the working phase, the contribution rate equals $\lambda^{\mathrm{DC}} 9$

The investor cannot short the stock market or take leveraged positions in it:

$$
\alpha_{i t}^{\mathrm{DC}} \in[0,1] .
$$

Before retirement, the law of motion for the DC account balance is:

$$
A_{i t+1}^{\mathrm{DC}}=A_{i t}^{\mathrm{DC}}\left(R_{f}+\alpha_{i t}^{\mathrm{DC}}\left(R_{t+1}-R_{f}\right)\right)+\lambda^{\mathrm{DC}} Y_{i t},
$$

Upon retirement at age 65 , withdrawal starts. We assume that the investor is allowed to make a one-time decision on the equity exposure for the remainder of her life (i.e., $\alpha_{i 65}^{\mathrm{DC}}=$ $\left.\alpha_{i 66}^{\mathrm{DC}}=\ldots=\alpha_{i 100}^{\mathrm{DC}}\right)$. Note that this variable becomes a state variable.

\section{Asset allocation in the DC account during working life}

We consider different rules for $\alpha_{i t}^{\mathrm{DC}}$ prior to retirement. Active investors who opt out are assumed to choose the equity share in the DC account fully rationally. Later we outline this dynamic programming problem in detail.

It is common to formulate investment rules that depend on age. One such rule is to invest the percentage 100 minus one's age in equity and the remainder in bonds. According to this rule, a 30-year-old would invest $70 \%$ in equities and a 70 -year-old would invest $30 \%$ in equities. We refer to this as the "100-minus-age" rule. This rule can be modified to have different equity exposures at the beginning of the working phase and in the retirement phase. We assume that default investors are exposed to an age-based equity share equal to "100-minus-age" during the working phase and $35 \%$ in the retirement phase. We then

\footnotetext{
${ }^{9}$ In line with the Swedish pension system, we implement the contribution as an employer tax. This means that the contributions do not show up as withdrawals from gross labor income in the individual's budget constraint. This is consistent with our calibration of the labor income process to micro data (i.e., our measure of gross labor income is net of the employer tax).
} 
contrast the consequences of this design to three alternatives:

1. The optimal equity share that conditions on all of the state variables in the model (i.e., apart from the cost associated with opting out it is equivalent to the allocation of an active investor who opts out).

2. A rule of thumb that conditions on a sub-set of observable characteristics that appear as state variables.

3. The average optimal age-based equity share (i.e., a glide path that conditions only on age and that equals the average optimal equity share).

\section{Notional account}

The law of motion for the notional account balance during the working phase is:

$$
A_{i t+1}^{\mathrm{N}}=A_{i t}^{\mathrm{N}} R_{f}+\lambda^{\mathrm{N}} Y_{i t}
$$

where $\lambda^{\mathrm{N}}$ is the contribution rate for the notional account.

To economize on state variables, we use $z_{i 64}$ to approximate the notional account balance at the time of retirement. This approximation is based on simulations of equations (6), (7), (9), and (15) to obtain the best fit between $z_{i 64}$ and $A_{i 64}^{\mathrm{N}}$ using regression analysis. This approximation works well. We provide further details in the Online Appendix.

\section{Annuitization of the pension accounts}

Upon retirement at age 65, the DC account and the notional account are converted into two actuarially fair life-long annuities. They insure against longevity risk through within-cohort transfers from individuals who die to surviving individuals. The notional account provides a fixed annuity with a guaranteed minimum. If the account balance is lower than is required to meet the guaranteed level at age 65 , the individual receives the remainder at age 65 in the form of a one-time transfer from the government. The annuity from the DC account is 
variable and depends on the choice of the equity exposure as well as realized returns. In expectation, the individual will receive a constant payment each year.

\subsection{Individual's problem}

Next we describe the individual's problem. To simplify the notation, we suppress the subscript $i$.

\section{Be active or stay in the default fund}

Let $V_{t}\left(X_{t}, A_{t}^{\mathrm{DC}}, z_{t}, \kappa, \kappa^{\mathrm{DC}}, I_{t-1}, I^{\mathrm{DC}}\right)$ be the value of an individual of age $t$ with cash on hand $X_{t}$, DC account balance $A_{t}^{\mathrm{DC}}$, a persistent income component $z_{t}$, cost for stock market entry $\kappa$, cost for opting out $\kappa^{\mathrm{DC}}$, stock market participation experience $I_{t-1}$, and whose activity in the $\mathrm{DC}$ account is $I^{\mathrm{DC}}$.

The individual chooses whether to remain in the default fund $\left(I^{\mathrm{DC}}=0\right)$ or to opt out $\left(I^{\mathrm{DC}}=1\right)$ :

$$
\max _{I^{\mathrm{DC}} \in\{0,1\}}\left\{V_{25}\left(X_{t}, 0, z_{25}, \kappa, \kappa^{\mathrm{DC}}, 0,0\right), V_{25}\left(X_{t}-\kappa^{\mathrm{DC}}, 0, z_{25}, \kappa, \kappa^{\mathrm{DC}}, 0,1\right)\right\}
$$

The decision to be active thus comes at a cost. The tradeoff for investors arises because staying in the default fund is costless but implies a sub-optimal asset allocation. Unlike the model of Carroll et al. (2009), the one-time opportunity to opt-out implies that there is no option value associated with waiting to take action.

\section{Active investor's problem}

The following describes the individual's problem when the equity share in the DC account is chosen optimally (i.e., conditional on all state variables) subject to paying the cost $\kappa^{\mathrm{DC}}$ (i.e., $I^{\mathrm{DC}}=1$ ). We refer to this as the active investors' dynamic programming problem. For 
brevity we introduce the notation $\Psi_{t}=\left(X_{t}, A_{t}^{\mathrm{DC}}, z_{t}\right)$.10

\section{Participant's problem}

An active investor who has already entered the stock market solves the following problem:

$$
V_{t}\left(\Psi_{t}, \kappa, \kappa^{\mathrm{DC}}, 1,1\right)=\max _{A_{t}, \alpha_{t}, \alpha_{t}^{\mathrm{DC}}}\left\{\left(\left(X_{t}-A_{t}\right)^{1-\rho}+\beta \phi_{t} \mathcal{R}_{t}\left(V_{t+1}\left(\Psi_{t+1}, \kappa, \kappa^{\mathrm{DC}}, 1,1\right)\right)^{1-\rho}\right)^{\frac{1}{1-\rho}}\right\}
$$
subject to equations (6)-(14).

\section{Stock market entrant's problem}

Let $V_{t}^{+}\left(\Psi_{t}, \kappa, \kappa^{\mathrm{DC}}, 0,1\right)$ be the value for an active investor with no previous stock market participation experience who decides to participate at $t$. This value is formulated as:

$$
\begin{aligned}
V_{t}^{+}\left(\Psi_{t}, \kappa, \kappa^{\mathrm{DC}}, 0,1\right)= & \max _{\begin{array}{c}
A_{t}, \alpha_{t}, \alpha_{t}^{\mathrm{DC}} \\
\text { subject to equations }
\end{array}}\left\{\left(\left(X_{t}-A_{t}-\kappa\right)^{1-\rho}+\beta \phi_{t} \mathcal{R}_{t}\left(V_{t+1}\left(\Psi_{t+1}, \kappa, \kappa^{\mathrm{DC}}, 1,1\right)\right)^{1-\rho}\right)^{\frac{1}{1-\rho}}\right\}
\end{aligned}
$$

\section{Non-participant's problem}

Let $V_{t}^{-}\left(\Psi_{t}, \kappa, \kappa^{\mathrm{DC}}, 0,1\right)$ be the value for an active investor with no previous stock market participation experience who decides not to participate at $t$. This value is formulated as:

$$
\begin{aligned}
V_{t}^{-}\left(\Psi_{t}, \kappa, \kappa^{\mathrm{DC}}, 0,1\right)= & \max _{A_{t}, \alpha_{t}^{\mathrm{DC}}}\left\{\left(\left(X_{t}-A_{t}\right)^{1-\rho}+\beta \phi_{t} \mathcal{R}_{t}\left(V_{t+1}\left(\Psi_{t+1}, \kappa, \kappa^{\mathrm{DC}}, 0,1\right)\right)^{1-\rho}\right)^{\frac{1}{1-\rho}}\right\} \\
& \text { subject to equations (6)-14. } .
\end{aligned}
$$

Note that as $\alpha_{t}=0$, the return on financial wealth is simply $R_{f}$.

\footnotetext{
${ }^{10}$ Notice that compared to working life, an additional state variable at ages 65 years or older is $\alpha_{65}^{\mathrm{DC}}$. For simplicity, we omit this variable from the value function.
} 


\section{Optimal stock market entry}

Given the entrant's and non-participant's problems, the stock market entry is given by:

$V_{t}\left(X_{t}, A_{t}^{\mathrm{DC}}, z_{t}, \kappa, \kappa^{\mathrm{DC}}, 0,1\right)=\max _{I_{t} \in\{0,1\}}\left\{V_{t}^{-}\left(X_{t}, A_{t}^{\mathrm{DC}}, z_{t}, \kappa, \kappa^{\mathrm{DC}}, 0,1\right), V_{t}^{+}\left(X_{t}-\kappa, A_{t}^{\mathrm{DC}}, z_{t}, \kappa, \kappa^{\mathrm{DC}}, 0,1\right)\right\}$

\section{Default investor's problem}

The default investor's problem is almost identical to the active's. There are only two differences. First, common to all default fund schemes is that default investors do not incur the $\operatorname{cost} \kappa^{\mathrm{DC}}$. Second, $\alpha_{t}^{\mathrm{DC}}$ is sometimes determined differently. If the equity share of the default fund is only a function of age (the unconditional optimal glide path or "100-minus-age") or a function of a subset of state variables (a rule of thumb), then the asset allocation is sub-optimal relative to the one implied by the active investor's dynamic programming problem. Only if the equity share of the default fund is fully customized and conditions on all of the state variables, then the default investor's asset allocation is identical to the active investors'.

\section{Portfolio choice outside the pension system}

In the main analysis, we assume full rationality. In the robustness analysis, we consider the consequences of investment mistakes outside the pension system.

\subsection{Calibration}

In this section we describe our calibration strategy. Table 4 reports the values of key parameters. Most parameters are set either according to the existing literature or to match Swedish institutional details; those parameters can be said to be set exogenously. Three sets

of parameters are used to match the data as well as possible; those parameters can be said to be determined endogenously. 


\section{Exogenous parameters}

There are six sets of exogenous parameters.

First, we set the equity premium to $4 \%$ per year and the standard deviation of the stock market return to $18 \%$ per year. These choices are in the range of commonly used parameter values in the literature. We set the simple risk-free rate to zero, which in other calibrations is often set to $1-2 \%$. We argue that this is correct in our model as labor income does not include economic growth. Thus, we deflate the account returns by the expected growth to obtain coherent replacement rates. As replacement rates in our model are a function of returns, rather than a function of final labor income, this choice is more important to the present model than to previous models. Simulations of the labor income process and contributions to the pension accounts validate our strategy. These simulations indicate that replacement rates at age 65 relative to labor income at age 64 are coherent with Swedish Pensions Agency forecasts.

Second, we set labor income according to Swedish data. We estimate the riskiness of the labor income after having added on common transfers (such as sick leave, unemployment and parental leave benefits) and after having subtracted taxes. Then we follow Carroll and Samwick (1997) but include year fixed effects to account for aggregate risk. We find that the standard deviation of permanent labor income equals 0.072 .11 We set the one-year correlation between permanent income growth and stock market returns to $10 \%$. This corresponds to a $\theta$ of 0.040 . We approximate the distribution of initial labor income and financial wealth using log-normal distributions. The mean financial wealth for 25-year-old default investors is set to SEK 76,800. The cross-sectional standard deviations are set to $0.366\left(\sigma_{z}\right)$ and 1.392 $\left(\sigma_{A}\right)$ to match the data for 25-year-old individuals.

Third, we consider the contribution rates. We set the contribution rate for the notional account to $16 \%$. We set the contribution rate for the DC account to $7 \%$. This mirrors the premium pension account with a contribution rate of $2.5 \%$ and the occupational pension account with a typical contribution rate of $4.5 \%$. We depart from the Swedish pension

\footnotetext{
${ }^{11}$ Since many transfer programs cover rents or subsidies of rents we also exclude individuals with a labor income less than SEK 48,000, consistent with the model's income floor.
} 
system by ignoring the ceilings in the contributions. However, about $90 \%$ of workers have occupational pension plans which compensate for the ceilings in the public plans in order to achieve high replacement rates also for high-income individuals.

Fourth, we determine the annuity divisor for the notional account in retirement. We use the unisex mortality table of Statistics Sweden to determine $\phi_{t}$. We assume that the notional account continues to be invested in the risk-free bond and allow for inheritances within a cohort from dying to surviving individuals, incorporating those into the returns of the survivors. We then use the standard annuity formula to reach an annuity factor of $5.6 \%$ out of the account balance at age 65 . We use the same formulas for the DC account, though we adjust the expected return to the endogenous choice of the DC equity share in retirement.

Fifth, we determine the DC equity share profile of the calibration. This is important because equity exposure in the pension system determines individuals' demand for equity outside the pension system, which we in turn match to be consistent with our data in 2007. The intrinsic difficulty is that all cohorts do not have equal equity exposure. To obtain a single life-cycle profile that can be used in the calibration, we mix the cohorts' profiles. Younger cohorts are given a greater weight in the early stages of the life-cycle and older cohorts are given a greater weight in the later stages. For practical purposes, a good fit turns out to be a linear profile such that the equity share equals to "100-minus-age" during working life and 35\% through the retirement phase. See the Online Appendix for further details.

Finally, we set the elasticity of intertemporal substitution to 0.5 , which is a common value in life-cycle models of portfolio choice (see, e.g., Gomes and Michaelides, 2005).

\section{Endogenous parameters}

Three sets of parameters are treated as endogenous in the calibration. $\mathrm{A} *$ in Table 4 marks these endogenous parameters. Table 5 reports matched moments in the data (from the 
working phase) and model ${ }^{12}$

First, the discount factor, $\beta$, is calibrated to match the 0.922 ratio of financial wealth to labor income. A discount factor of 0.933 provides a close fit to the data. The top-left panel of Figure 1 shows the full life-cycle profile of financial wealth. The model fits the financial wealth reasonably well - it undershoots somewhat up to age 42 and overshoots after that.

Second, the relative risk aversion coefficient, $\gamma$, determines the conditional equity share. We weigh the equity shares of each age group by its financial wealth. A relative risk aversion of 14 provides a reasonable fit. We consider an equity premium of $2 \%$, which allows for a lower relative risk aversion coefficient, in the robustness analysis. The value-weighted conditional equity share is 0.454 in the data and 0.519 in the model. The lower-left panel of Figure 1 depicts the life-cycle profile. The model overshoots early in the life-cycle and undershoots the ten years before retirement. This is a common feature of life-cycle portfolio choice models. We consider alternative specifications in the robustness analysis in which the investor makes random allocation mistakes or has the equity share in the data. We are reluctant to increase the relative risk aversion further, as this would lead to a worse discrepancy close to retirement age. In the model there is a noticeable increase in the equity share after age 70. However, if value-weighted, this increase is negligible as the financial wealth is then small.

Third, we endogenously calibrate the joint distribution of the two costs, $\kappa$ and $\kappa^{\mathrm{DC}}$, to the joint distribution of active/passive and participating/non-participating investors which is a total of four moments (they sum to one). For computational ease, we approximate each distribution with five equally spaced values, which in turn enables us to include up to 25 different combinations forming a $5 \times 5$ matrix. We give each included type the same weight. For each cost, we let the lower support be given by zero. The upper support of $\kappa$ is determined by the share of non-participation in the data (48.1\%) and the upper support of $\kappa^{\mathrm{DC}}$ is determined by the share of passive investors $(60.5 \%)$. The shares imply an upper

\footnotetext{
${ }^{12}$ Note that we match the model to data from 2007. This does not allow us to extract cohort or time effects as in, e.g., Ameriks and Zeldes (2004). However, Vestman (2015) finds that cohort and time effects are not strongly present in the data.
} 
support of $\kappa$ equal to SEK 15,600 and an upper support of $\kappa^{\mathrm{DC}}$ equal to SEK 3,600. The cost associated with opting out is smaller because the benefits of doing so only accrue in forty years time. The share of investors that are active and participate (24.4\%) and the share of investors that do not participate and who are passive (33.0\%) determine the correlation between the two costs. If we were to include all 25 combinations, the correlation between $\kappa$ and $\kappa^{\mathrm{DC}}$ would be zero and the correlation between non-participation and default investing would be determined entirely by observable characteristics such as financial wealth and labor income. If we were to include only the diagonal elements of the $5 \times 5$ matrix, the correlation between the costs would be one. In order to systematically determine which of the 25 types of combinations of $\kappa$ and $\kappa^{\mathrm{DC}}$ to include we start from the case of a perfect correlation along the diagonal of square and then add types in layers further and further away from the diagonal to achieve the best fit of the share of active participants and passive non-participants. The best fit is obtained when including three layers on each side of the diagonal (i.e., when including 23 types). The matrix below illustrates this process:

\begin{tabular}{c|ccccc}
$\bar{\kappa}^{\mathrm{DC}}$ & 4 & $\mathbf{3}$ & $\mathbf{2}$ & $\mathbf{1}$ & $\mathbf{0}$ \\
& $\mathbf{3}$ & $\mathbf{2}$ & $\mathbf{1}$ & $\mathbf{0}$ & $\mathbf{1}$ \\
& $\mathbf{2}$ & $\mathbf{1}$ & $\mathbf{0}$ & $\mathbf{1}$ & $\mathbf{2}$ \\
0 & $\mathbf{1}$ & $\mathbf{0}$ & $\mathbf{1}$ & $\mathbf{2}$ & $\mathbf{3}$ \\
0 & $\mathbf{0}$ & $\mathbf{1}$ & $\mathbf{2}$ & $\mathbf{3}$ & 4 \\
\hline & 0 & & & & $\bar{\kappa}$
\end{tabular}

where the elements on the diagonal and the three layers on each side of the diagonal are in bold. Equal weight on these 23 types implies a correlation between $\kappa$ and $\kappa^{\mathrm{DC}}$ of 0.2 . Moreover, as we use a square matrix the two marginal distributions have the same shape and are symmetric around their means and modes (which are equal to SEK 7,800 for the participation cost and SEK 1,800 for the opt-out cost). We find our modeling approach appealing as it enables us to keep the costs low for the average investor (see Vissing-Jørgensen, 2002). 


\section{Simulation method and model fit}

There are two main sources of risk in our model: (i) aggregate equity returns and (ii) idiosyncratic labor income shocks. Our simulation method lets us separately study the two risk sources. For each of the 23 types, we consider 500 individuals with different idiosyncratic labor income shocks. So in total there are 11,500 individuals in an economy. The 23 individual types share the same income realization but have different costs. Strictly speaking, an economy is a single birth cohort, which we follow over its life. The economy faces one equity return realization of 75 annual returns, common to all individuals in the economy. We simulate a total of 50 economies.

When we take the average for each individual over the 50 economies, we obtain ex ante life-cycle profiles of 11,500 individuals; this distribution represents the inequality across individuals. When we instead take the average for each economy over the 11,500 individuals, we are able to analyze the role of aggregate equity risk. When we compute averages over both sources of risk we obtain unconditional averages. We simply refer to them as averages ${ }^{13}$

Figure 2 demonstrates the model's ability to endogenously produce a sorting of individuals in terms of average labor income and financial wealth. The top-left panel illustrates the model's ability to produce a gap in labor income between opt-out and default investors that is very similar to the data. The top-right panel displays a similar gap in financial wealth between opt-out and default investors. The bottom-left panel shows labor income for participants and non-participants. The gap in the model is qualitatively very similar to the gap in the data (it widens a little too much late in the working phase). The bottom-right panel shows that the model generates a substantial gap in financial wealth too, starting from age 40. We find the fit remarkable considering that neither labor income nor financial wealth of any sub-group of investors are targeted in the calibration.

\footnotetext{
${ }^{13}$ For every economy, the same idiosyncratic income shocks are used. The cross-sectional average of these shocks is zero for each year. Furthermore, we re-use the idiosyncratic income shocks and stock market returns for all cost types and all designs of the default fund. We also re-use initial draws of $z_{i 25}$ and $A_{i 25}$. This simulation method is similar to that of Campbell and Cocco (2015), who also distinguish between aggregate and idiosyncratic shocks.
} 


\section{Optimal design}

In this section we first report who the default investors are and discuss the optimal design for these investors. We then consider how the optimal asset allocation responds to realized equity returns and to labor income shocks. Initially, the default investors arise from the "100minus-age" allocation. Later on we illustrate the optimal allocation for different groups of default investors that have endogenously arisen under other default designs. For each of these designs, and groups of default investors, we report the welfare implication of implementing an even more customized default. The optimal design is a counterfactual outcome: it answers the question which asset allocation a given group of default investors prefers the most.

\subsection{Who are the default investors?}

Our model allows the opt-out/default choice to be shaped by both observable and unobservable characteristics, as in the data. We begin by reporting the effect of these characteristics on the choice.

Taking opt-out and default investors together, the average cost for opting out is SEK 1,800. However, for default investors the average is SEK 2,500 and for opt-out investors it is SEK 800. In addition, there is substantial variation within the investor groups. For example, default investors' opt-out costs fall in the range of SEK 900 to SEK 3,600 (with corresponding opt-out rates of $66 \%$ and $2.8 \%$ ). Moreover, there is a substitution effect between the two costs. Among investors with a zero participation cost and an opt-out cost of SEK 900, the share of opt-out investors is $43 \%$. Among investors with a participation cost of SEK 15,600 and an opt-out cost of SEK 900, the share of opt-out investors is $83 \%$. That many investors opt out even if they have no cost for participating in the stock market outside of the pension system suggests that financial wealth and the DC account are imperfect substitutes. The Online Appendix reports the share of opt-out investors for each of the 23 cost types.

As discussed above, observable characteristics, such as labor income and financial wealth, also matter for the opt-out/default decision. We have further investigated their relevance. In an untabulated regression with the opt-out decision as the dependent variable and linear 
terms for labor income and financial wealth we find both characteristics to have a positive

effect. However, labor income is economically more important. An increase in labor income (financial wealth) of SEK 10,000 increases the likelihood of opting out by 3.3 (0.6) percentage points. We interpret this as an artifact of the DC account being particularly important for high-income investors. The relative importance of labor income versus financial wealth (a factor of five) is similar to what we found in the data.

\subsection{Optimal asset allocation for default and opt-out investors}

Figure 3 shows averages of all model outcomes for default and opt-out investors under the optimal asset allocation. The default and opt-out investors are endogenously shaped from the "100-minus-age" default design but for the default group we report their optimal asset allocation. Recall that the optimal asset allocation for default investors is a counterfactual. Hence, the paths represent what the default investors would do if they were able to opt out at no cost.

The top-left panel reports labor income during the working phase and pension (i.e., annuities from the DC and notional accounts) during the retirement phase. For default investors, the average labor income at age 64 is SEK 181,900 and the average pension is SEK 152,300 (yielding a replacement rate of 84\%). Opt-out investors earn more during working life but have a lower replacement rates in retirement (74\%). The top-right panel shows consumption, which is hump shaped as individuals do not fully smooth their consumption.

The three following panels show the notional account, the DC account, and financial wealth, all of which are distinctly built up during the working phase and then depleted. The high contribution rates for the two pension accounts make their balances large relative to financial wealth even at a young age. Already before age 30, the DC account is as large as the financial wealth. The importance of the DC account then increases. For default investors at age 65 their DC account is 2.9 times as large as their financial wealth. In relative terms, opt-out investors' DC account is not as important to sustain consumption in retirement. At age 65 , the account is 1.9 times as large as financial wealth. This is one reason for the higher 
replacement rate among default investors. The other reason is that the guarantee on the annuity out of the notional account more often binds for default than for opt-out investors. This is manifested as a jump in the profile for the notional account between ages 64 and 65 for default investors.

The magnitude of the DC account relative to financial wealth and relative to the notional account illustrates how potent the optimal asset allocation of the default fund is: The total equity exposure will essentially be determined by the equity share in the DC account. Financial wealth mainly serves as a buffer for precautionary savings motives, peaking just before retirement and then quickly depleting. While the notional account is the largest account, the DC account catches up over time due to its equity exposure.

The third panel on the right illustrates the stock market participation rate for default and opt-out investors. Default investors display a gap relative to opt-out investors of at most 20 percentage points during working life (80 versus 60 percentage points beginning at age 42 and continuing until retirement).

The bottom-left panel shows the equity share in financial wealth conditional on participation. This is the equity share outside the pension system. It first increases slightly and then decreases until retirement when it jumps. The increase up to age 35 is driven by selection. As wealth-poorer households enter they can tolerate a higher conditional equity share. Around age 40 the sample of participants stabilizes and the conditional equity share gradually falls. As the present value of labor income diminishes and financial wealth increases, a high equity share cannot be tolerated (Merton, 1971; Cocco et al., 2005). After retirement, individuals tolerate a somewhat higher equity exposure. Note that the increase in the conditional equity share after retirement is economically not so important as the financial wealth is then low.

Finally, the bottom-right panel shows the DC equity share for default and opt-out investors. At age 25 it is $100 \%$. It remains high until age 35 when it starts to decrease almost linearly. Notably, the change is greater for opt-out investors than for default investors. By age 45 there is a gap of 15 percentage points between default and opt-out investors where default investors are on a more aggressive path than opt-out investors. The main takeaway is that the endogenous selection into the default fund has implications for the optimal DC 
equity share. From age 35 and onwards, default investors prefer a more aggressive allocation than opt-out investors. The average DC equity share fits well with target-date (or life-cycle) funds offered by mutual fund families such as Fidelity and Vanguard. The equity share in their funds is typically around 80-90\% until 30 years before retirement (at age 35 in our model) and then the equity share declines by 1.5-2 percentage points per year until retirement (at age 65 in our model). Even if the average equity share of the model fits well with the allocation of target-date funds, the model average masks a lot of variation which we explore in the remainder of the paper.

\subsection{Equity risk and inequality}

Figure 4 shows the aggregate equity risk and inequality implied by the optimal asset allocation for default investors. The panels to the left refer to averages over individuals, highlighting the equity risk; the panels to the right refer to averages over economies, highlighting the inequality across individuals that arise due to idiosyncratic labor income shocks. We sort the variables by the DC equity share in each of the top panels, maintaining that sorting for the remaining panels. As before, the default investor sample is an outcome of a default design equal to "100-minus-age."

The top-left panel shows how the DC equity share varies over the economies, i.e., how much it varies with the realized equity returns. The second decile indicates that, with a probability of at least 10\%, the DC equity share exceeds $34 \%$ throughout the working phase, jumping to approximately $44 \%$ at retirement. The ninth decile indicates that, with a probability of at least $10 \%$, the DC equity share decreases below $20 \%$ before retirement, jumping approximately to $30 \%$ at retirement. The panel below shows the corresponding values for the DC account. It indicates a strong negative correlation between the DC equity share and the DC account balance, a high equity share corresponding to a low account balance and vice versa. The remaining three panels to the left show the corresponding values for labor income and pension, financial wealth, and stock market participation. None of these variables seems to covary as strongly with the DC equity share as does the DC 
account balance.

As the DC equity share correlates negatively with the DC account balance while labor income (and hence contributions to the DC account) does not, the analysis suggests that realized equity returns affect the optimal asset allocation. A small difference in returns over many years results in large differences in DC account balances. For example, assuming that contributions are constant, the effective annual rate is 0.7 percentage points above expectations for economies in the ninth decile and 0.9 percentage points below expectations for economies in the second decile. This seemingly small difference in realized returns and large difference in DC equity share implies that the optimal allocation involves active rebalancing. As returns exceed expectations, it is optimal to invest less in equity and vice versa. The mechanism behind this property of the optimal allocation is that a key determinant of the DC equity share is the value of the DC account relative to other accounts and relative to the present value of labor income. The high sensitivity to realized returns means that the optimal equity share can differ markedly between cohorts that have experienced different return histories.

The top-right panel shows the inequality in the DC equity share. The first decile has the highest DC equity share and the tenth has the lowest. We report the second and the ninth decile. The second decile has an average DC equity share that stays above $60 \%$ until age 53 and then declines to $39 \%$ just before retirement. At retirement, the DC equity share jumps to $46 \%$. The ninth decile has an average DC equity share that is $18 \%$ at age 50 and declines below $9 \%$ at age 64 ; at retirement, the DC equity share jumps to $26 \%$. Notably, the gap between the second and ninth deciles widens already at age 40 (when it is more than 30 percentage points) and it is substantial among 50-year-old investors (when it is 60 percentage points).

The four panels below show how the inequality in DC equity shares relates to other characteristics. Individuals with a high optimal DC equity share have low DC account balances and are somewhat income poor, and are unlikely to participate in the stock market; individuals with a low optimal DC equity share have high DC account balances, are somewhat income rich, and are likely to participate in the stock market. In an unreported graph we 
also plot the ratio of the DC account balance to labor income. For default investors younger than 50 there is little difference between the second and ninth decile in terms of this ratio, suggesting a selection effect in terms of participation. Later in life, from age 50 and onwards, the second decile has a low ratio and the ninth decile a high ratio which is consistent with standard models (Merton, 1971; Cocco et al., 2005).

To sum up, variation across economies implies that equity return realizations matter for the DC equity share. This means that different birth cohorts have different optimal allocations at the same age. Moreover, the large cross-sectional dispersion in optimal equity shares emphasizes the potential of an asset allocation conditional on investor-specific characteristics. In other words, different default investors have different needs.

\subsection{Mass-customization: A rule of thumb beyond age}

In this section we approximate the optimal design with linear regressions on observable characteristics. The purpose is that such a regression specification offers a rule of thumb (i.e., it is a tool to achieve a rule that is easy to implement). It effectively provides a means to achieve rule-based mass-customization.

As a complement to our previous illustration of equity risk and inequality, we regress the optimal equity share of default investors on their characteristics. More specifically, we run the following regression on model-generated data:

$$
\alpha_{i t}^{\mathrm{DC}}=\beta_{0}+\beta_{1} t+\beta_{2} A_{i t}+\beta_{3} A_{i t}^{\mathrm{DC}}+\beta_{4} Y_{i t}+\beta_{5} I_{i t}+\varepsilon_{i t},
$$

where the dependent variable is the optimal DC equity share of individual $i$ of age $t$, and where all covariates are state variables of the model. Note that $A_{i t}$ and $A_{i t}^{\mathrm{DC}}$ are functions of both idiosyncratic income shocks and aggregate equity returns. We do not include the $\operatorname{costs}, \kappa_{i}$ and $\kappa_{i}^{\mathrm{DC}}$, as they would be unobservable in actual data. We run the regression on individuals during their working phase. Note that the $R$-squared in the regression captures the efficiency of the investment rule relative to the optimal equity share that conditions on all state variables in the model. 
This analysis relates to Merton (1971), who derived the intertemporal hedging motive that arises from the present discounted value of labor income. Cocco et al. (2005) discuss the role of financial wealth relative to total wealth (including the present value of labor income) when labor income is uninsurable. In our model the value of the three accounts $\left(A_{i t}, A_{i t}^{\mathrm{DC}}\right.$, and $\left.A_{i t}^{\mathrm{N}}\right)$ and the present value of labor income guide optimal equity shares inside and outside the pension system. If the aim was to contrast our model to theirs, we could report the total equity share as a function of account balances and labor income. Since some of our accounts remain illiquid until retirement, the result would not be entirely identical. Note, for instance, that if equity returns are high and the balance on the DC account increases, it is not possible to consume out of the account during the working phase. However, the purpose of our analysis is to obtain an asset allocation rule which is implementable for a designer of a default fund. We therefore focus on different subsets of the state variables and do not include wealth ratios in the analysis. Related to this, Dammon et al. (2004) focus on the optimal equity share in a tax-deferrable (retirement) account as a function of age and account balance.

Table 66reports the regression results using different specifications. Specification I mimics the simple age-based investment rule. The estimate suggests that individuals should decrease their DC equity exposure by 2.4 percentage points every year. This linear specification is admittedly a crude regression specification, because it results in many young individuals being forced into a DC equity share of $100 \%$. The estimated intercept indeed implies that the predicted DC equity share for a 25 -year-old is $114.6 \%$. Nevertheless, the interpretation is that a better rule for the DC equity share would be to have it at 100\% until about age 30 and thereafter let it fall by 2.4 percentage points per year. Note that this is a steeper reduction in equity exposure over time than that of the "100-minus-age" rule. Interestingly, the $R$-squared for our rule is as high as $63.0 \%$. In untabulated results, we find that non-linear specifications in age only improves the $R$-squared marginally.

To better understand the role of incremental information in the form of additional state variables, Specifications II-V add one additional state variable at a time to the age variable. All additions significantly improve the regression fit. In Specifications II and III, labor 
income and financial wealth add six and eleven percentage points to the $R$-squared. The stock market participation status in Specification IV adds ten percentage points, and the estimates suggest that stock market participants should have 23.3 percentage points less exposure to equity than do non-participants, a substantial difference. However, the single most influential state variable is the DC account balance. Specification V shows that the DC equity share should be reduced by 0.9 percentage points per year as a direct effect of age. The remaining reduction is contingent on the development of the account balance. In addition to the direct effect, the DC equity share should be reduced by 6.7 percentage points for every increase of SEK 100,000 in the account balance. This increase is in turn a function of the contribution to the account (i.e., labor income) and the realized equity return. The $R$-squared associated with this simple asset allocation rule increases by 16 percentage points relative to Specification I, implying that the rule can account for an impressive $78.6 \%$ of the variation in the optimal allocation. It is particularly encouraging that the account balance is the single best piece of incremental information, as it is directly observable.

Specification VI shows the effects of the rule based on both the DC account balance and stock market participation. The optimal rule can be stated as follows: Reduce the DC equity share by 0.8 percentage point every year. In addition, reduce the DC equity share by 6.0 percentage points for every SEK 100,000 invested in the account. Finally, reduce the life-cycle path by 19.6 percentage points if the individual is a stock market participant. This rule summarizes the model implications well and accounts for $85.5 \%$ of the model's optimal asset allocation rule. The $R$-squared for Specification VII reveals that labor income and financial wealth add little on the margin.

\subsection{Welfare effects}

We next analyze the welfare effects that arise from implementing a more and more customized default design. Along with the welfare effects we also analyze the endogenous change in the shares of default and opt-out investors. 


\section{Three default designs and three groups of default investors}

We gradually increase the customization: we start from the baseline calibration "100-minusage" and its sample. This is our first allocation rule and default investor sample $(58.7 \%$ of all individuals). Based on the optimal design for this sample, we obtain the average optimal age-based rule, which represents the best purely age-based rule for default investors in our model. The bottom-right panel of Figure 3 reports its glide path. Based on this design, we obtain a second sample of default investors. The share of default investors is expected to be greater as the default is closer to the optimal allocation. From this sample we estimate a rule-of-thumb allocation using specification VI in Table 6. We implement this rule of thumb and obtain a third sample of default investors. Finally, we report results for the optimal design. Again, we expect the share of default investors to increase further as the rule of thumb involves even more customization. For each incremental shift in customization we report the welfare gain relative to the previous design and the share of default investors. We report effects for the sample of individuals that stay in the default under "100-minus-age" unless otherwise noted.

\section{Increasing share of default investors and responses to the optimal design}

The first row of Table 7 reports how the share of default investors increases as the degree of customization of the design increases. Shifting the glide path to average within the model increases the share by 9.2 percentage points to $67.9 \%$. Shifting the design from the average to the rule of thumb further increases the share of default investors by 7.4 percentage points

to $75.3 \%$. Put differently, the implementation of the rule of thumb induces an endogenous response so that the share of opt-out investors is reduced from $41.3 \%$ to $24.7 \%$.

A central insight is that the groups of opt-out and default investors are endogenously generated. They have arisen as an endogenous response to a particular default design and institutional setting. Carroll et al. (2009) study how the optimal design depends on the underlying characteristics of the default group (e.g., whether they are procrastinators or whether they lack financial literacy). We have a limited ability in exploring such differences. 
However, we explore how the optimal default design changes across our samples of default investors that arose from different default designs. The default investors are less negatively selected the more customized the default fund is. Considering, the life-cycle paths for the sub-optimal default designs, labor income peaks at SEK 261,400 under the "100-minusage" design and at SEK 282,200 under the rule of thumb. The corresponding numbers for financial wealth are SEK 365,500 and SEK 423,700. Despite of these fairly large differences, the discrepancy of the average DC equity share is small - at most three percentage points in mid-working life. We view this a quite encouraging. It indicates that the optimal DC equity share seems robust to particular historical default designs.

\section{Welfare}

Welfare is our main metric for evaluating improvements to the design of the default fund. We report welfare effects based on ex ante increases in certainty-equivalent consumption during the retirement phase. In other words, the welfare gain is measured as the percent increase in certainty-equivalent consumption during retirement, viewed from the perspective of a 25 year-old investor. That is, the 25 year-old investor is promised the same consumption during the working phase but promised different consumption levels during the retirement phase. The main advantage of this measure is that it trades off increases to returns (i.e., pension income) and increases to risk (in returns and pension income) in a consistent manner. (In contrast, if we were to maximize the average ex post replacement rate it would suffice to max out the allocation to equity.) It also captures any benefits to re-optimization during the working phase. The Online Appendix explains how we derive this measure based on the investors' value function.

The second row of Table 7 reports the incremental increases of welfare as the design becomes more customized. Moving from "100-minus-age" to the average optimal glide path increases investors' welfare by $0.3 \%$ on average. However, this effect is small in comparison to the effect of moving from the average optimal to the rule of thumb, which implies a gain of $0.6 \%$. Finally, moving from the rule of thumb to the true optimal adds an incremental effect 
of $0.6 \%$. The total effect of moving from "100-minus-age" to the optimal allocation is thus 1.5\%. This is a sizeable gain for this class of incomplete market models. As a comparison, Campbell and Cocco (2015) report a 1.1\% welfare gain of offering adjustable rate mortgages in high yield states. Furthermore, unlike many other reforms (such as tax reforms or reforms to unemployment insurance) an increasing degree of customization is Pareto improving. Ex ante there are no losers from a better design. We find that the range of the total welfare gain ("100-minus-age" to optimal) is between $0.9 \%$ and $2.9 \%$. In unreported analysis we have also investigated how much individuals who switch from opting out to being default investors gain relative to those who already were default investors. Switchers only gain 0.1 percentage points more which reassures us that the results are not driven by reductions in the cost of opting out (i.e., that fewer individuals pay the $\operatorname{cost} \kappa_{i}^{\mathrm{DC}}$ ). Moreover, we have checked that the gross flow of individuals between the opt-out group and the default group is not greater than the net flow. No default investors abandon the default fund and opt out as customization increases.

We emphasize that moving from a sub-optimal age-based investment rule (such as "100minus-age") to the rule of thumb achieves a large share (60\%) of the potential welfare gain of implementing the optimal design. Furthermore, it turns out to be of little importance to tailor the rule precisely to a particular endogenous sample of default investors. The bottom panel of Table 7 reports regression results. For any of our samples of default investors the rule is quite similar - the differences are not economically meaningful. This is compelling for two reasons. First, the similarity further supports our previous argument that the optimal default design seems robust to particular initial sub-optimal default offerings. Second, it indicates that a simple rule of thumb can assist plan sponsors in achieving mass-customization.

\subsection{Effects on pension income}

The optimal design trades off risk and return perfectly. To understand how this impacts pension income the bottom panel of Table 7 reports average pension, equity risk, and inequality for the four alternative designs of the default fund. The former measure is an average over 
individuals and over economies. The latter two measures are standard deviations of log pension income, either computed across economies or across individuals. Notably, average pension is not affected very much by customization. It is highest for the rule of thumb but lowest in the optimal design. However, the variation is small compared to the variation in equity risk and inequality. Inequality is reduced by $16 \%$ in the optimal design and equity risk is reduced by $28 \%$. The bottom line is that the optimal default mainly reduces excess equity risk and provides a means to reduce inequality, while maintaining approximately the same average pension income.

Our proposed linear rule of thumb is a little coarse in terms of managing equity risk. It offers the most equity risk and hence the average pension is high under its implementation. The reason is that linearity implies that the equity exposure late in life exceeds the optimal design. It is easy to formulate an extended rule that corrects this and provides an average pension, equity risk, and inequality which lie in between the average optimal and the optimal design. Designers will need to trade off simplicity with accuracy.

\subsection{Robustness}

We investigate how our main results are affected as we make alternative assumptions in our model. Importantly, we re-calibrate our model to these assumptions in order to maintain the best possible fit for the targeted moments in data. We report the details of the alternative calibrations, the targeted moments, and the main results in the Online Appendix.

We find that our main results hold both qualitatively and quantitatively throughout the exercises. In particular, the welfare gain, the fraction of it that can be achieved by either using the optimal average allocation or the rule of thumb, and the changes in the fraction of investors who opt out, are all similar to those for the benchmark case.

\section{Sub-optimal portfolio choice outside the pension system}

In our main analysis, we let stock market participants allocate their portfolio optimally outside of the pension system. We view this as a natural baseline as the implementation of 
any systematic sub-optimal behavior outside the pension system would increase the value of a well-designed default allocation inside the pension system. However, empirical evidence suggests that investors lack knowledge of different asset classes' risk-return properties and consequently how to form their portfolio (see, e.g., Carrol et al., 2009). Empirical evidence also suggests that individuals make savings and allocation choices in one account independently of what is happening in other accounts (Choi et al., 2009; Card and Ransom, 2011; Chetty et al., 2014). We therefore analyze if our results are affected by the assumption that individuals make mistakes outside the pension system. More specifically, we consider three kinds of mistakes.

First, we assume that individuals who participate in the stock market hold a constant fraction of their financial wealth in equity. We let this fraction be equal to the mean in the data $(43.2 \%)$. This fraction is thus set independent of their value of financial wealth, their labor income, the value of their DC account and in particular its asset allocation, or of their age. (As a consequence, the value of being a stock market participant decreases so we recalibrate the upper support for $\kappa$ to SEK 5,400.) Under this behavior the value of a customized default in the DC account increases. Moving from "100-minus-age" to the optimal design implies a welfare gain of $2.1 \%$. Implementation of the rule of thumb implies that half of this gain is attained.

Second, we assume that individuals who participate in the stock market make random allocation mistakes. That is, unlike in the first analysis, there is variation in the crosssection. We implement this as an exogenous time-invariant state variable. Individuals are pre-destined to hold one of five equity shares if they choose to become stock market participants. The five values correspond to the mean of each quintile in the cross-sectional distribution. That individuals are aware of their tendency to make mistakes is consistent with the argumentation by Calvet, Campbell, and Sodini (2007). Just as for $\kappa$ and $\kappa^{\mathrm{DC}}$ we assume that the designer of the default fund cannot observe these five types when implementing the rule of thumb. This is a considerably tougher robustness exercise, as it treats the behavioral mistake as unobserved to the default designer. Consequently, we find in an untabulated regression that the gap between participants' and non-participants' optimal eq- 
uity shares decreases as participation is less informative about the equity exposure outside the pension system. Nevertheless, the value of the optimal default compared to "100-minusage" in this exercise is $2.3 \%$. In the implementation of the rule of thumb, the share of the gain is $52 \%$. The exercise suggests that even if with cross-sectional unobserved variation in sub-optimally chosen equity shares there is a lot to be gained from customizing the default fund.

Third, we mimic random stock market participation. We do so in a simple fashion by letting $\kappa$ in the cross-section be either zero or SEK 15,600. The variation in $\kappa^{\mathrm{DC}}$ is preserved as in the main calibration. In this exercise, the participation rate increases somewhat to $56 \%$. Our results and message remain intact.

These results illustrate how a wise default can compensate for systematic portfolio choice mistakes outside the pension system. The results also illustrate the robustness of the analysis.

\section{Alternative processes for equity returns and model misspecification}

It is well-documented that equity returns are left-skewed. In life-cycle portfolio-choice models this feature has been implemented as a small probability of a disaster shock to equity returns (see, e.g., Alan, 2012, and Fagereng et al., 2015). We follow the approach of Judd et al. (2011) and modify the equity return distribution so that an annual return of $-41 \%$ (expected return minus two and a half standard deviations) is drawn with a $2 \%$ probability. We find our main results to be robust to this modification. At $1.5 \%$, the total welfare effect is essentially unaffected. The rule of thumb accounts for as much as $60 \%$ of the total welfare gain.

The most common choice for the equity risk premium in portfolio choice models is $4 \%$ as in our baseline calibration. We investigate how our results depend on its magnitude by decreasing it to $2 \%$. Note that a lower equity premium comes with a lower risk aversion, so this case is also a robustness check on the importance of a high risk aversion. Our main results on welfare are insensitive to this change. The welfare gain associated with a shift from "100-minus-age" to optimal is $1.6 \%$, where $63 \%$ of it can be attained by the rule of thumb. The changes to the opt-out rates from offering incremental customization are also 
unaffected. That the results are robust to this change is not obvious. On the one hand, equity and bonds become more similar in terms of expected return and thus the asset allocation decision becomes less potent. On the other hand, it may be valuable to extract even a small equity premium in states in which risk averse individuals can tolerate it. These two effects net out in our model.

We also consider the effects of model misspecification along these dimensions, analogous to Michaelides and Zhang (2015). We implement the benchmark estimates for the rule of thumb (i.e., column 2 of Table 7) and in a model with either of the deviations. Even with such a misspecified rule of thumb, there are no economically meaningful differences.

\section{Share of default investors}

In our baseline analysis, we calibrate the model so that $58.7 \%$ of pension investors remain in the default fund. While we argue that this is a fair reflection of the empirical pattern of investors' passivity, we recalibrate the model so that the share of default investors reflect the $32.8 \%$ of default investors in the data. In this setting, the welfare gain of implementing the optimal design increases slightly from $1.5 \%$ to $1.7 \%$. Furthermore, the share attainable by the rule of thumb increases from $60 \%$ to $65 \%$. We view this as a consequence of default investors becoming endogenously more negatively selected.

\section{Concluding remarks}

We examine the effects of different equity exposures in the default fund in a defined contribution plan whose investors are heterogeneous and endogenously determined.

Using detailed data on individuals and their holdings inside and outside the pension system, we compare different investor types. We find that passive investors are less educated, have less labor income, have less wealth, and are more reliant on their pension savings than active investors. Taken together, passive investors can be viewed as less sophisticated on average. The observable characteristics capture a large part, but not all, of the unconditional differences in stock market participation. We also find that there is great heterogeneity 
among passive investors and that stock market participation serves as an indicator for high labor income and financial wealth.

Following these findings, we set up a life-cycle model that captures the economic situation of investors. The model has standard building blocks such as risky labor income, independently and identically distributed returns to equity, a consumption-savings decision, and a portfolio choice. We augment the standard model with a pension system in which individuals save in illiquid pension accounts from which their pension is received as annuities. We also augment the model with an endogenous opt-out/default choice. In sum, the model provides realistic heterogeneity over labor income, financial wealth, and stock market participation across opt-out/default investors. We use the model to discuss the optimal asset allocation of the default fund for samples of default investors that have arisen under varying default offerings.

Relative to a common age-based allocation rule, "100-minus-age," the average ex ante welfare gain of implementing the optimal asset allocation equals $1.5 \%$. We explore how the optimal design relates to other characteristics in addition to the age of the investor. We find that age is indeed important but that the optimal rule also relies heavily on the pension account balance and stock market participation outside the pension system. Most of the welfare gain is attainable by implementing a simple rule of thumb that conditions on these three characteristics. Our model suggests that $40 \%$ of active investors would choose the default fund under such a design. We find this to be a promising avenue for masscustomization. We encourage pension agencies and plan sponsors to study the practical and legal aspects of designing a default fund based not only on age but also on other observable characteristics. 


\section{References}

Alan, Sule, 2006, Entry Costs and Stock Market Participation Over the Life Cycle, Review of Economic Dynamics 9, 588-611.

Alan, Sule, 2012, Do Disaster Expectations Explain Household Portfolios?, Quantitative Economics 3, 1-28.

Ameriks, John, and Stephen P. Zeldes, 2004, How Do Household Portfolio Shares Vary With Age?, Working Paper.

Benartzi, Shlomo, and Richard H. Thaler, 2001, Naive Diversification Strategies in Defined Contribution Saving Plans, American Economic Review 91, 79-98.

Benartzi, Shlomo, and Richard H. Thaler, 2007, Heuristics and Biases in Retirement Savings Behavior, Journal of Economic Perspectives 21, 81-104.

Bergstresser, Daniel, and James Poterba, 2004, Asset Allocation and Asset Location: Household Evidence from the Survey of Consumer Finances, Journal of Public Economics 88, 1893-1915.

Bodie, Zvi, Jérôme Detemple, and Marcel Rindisbacher, 2009, Life-Cycle Finance and the Design of Pension Plans, Annual Review of Financial Economics 1, 249-260.

Bodie, Zvi, Robert C. Merton, and William F. Samuelson, 1992, Labor Supply Flexibility and Portfolio Choice in a Life Cycle Model, Journal of Economic Dynamics 85 Control 16, 427-449.

Calvet, Laurent E., John Y. Campbell, and Paolo Sodini, 2007, Down or Out: Assessing the Welfare Costs of Household Investment Mistakes, Journal of Political Economy 115, $707-747$.

Calvet, Laurent E., John Y. Campbell, and Paolo Sodini, 2009, Fight or Flight? Portfolio Rebalancing by Individual Investors, Quarterly Journal of Economics 124, 301-348.

Campanale, Claudio, Carolina Fugazza, and Francisco Gomes, 2014, Life-Cycle Portfolio Choice with Liquid and Illiquid Financial Assets, Journal of Monetary Economics 71, $67-83$.

Campbell, John Y., 2016, Restoring Rational Choice: The Challenge of Consumer Financial Regulation, American Economic Review, Papers 8 Proceedings 106, 1-30.

Campbell, John Y., and João F. Cocco, 2015, A Model of Mortgage Default, Journal of Finance 70, 1495-1554.

Card, David, and Michael Ransom, 2011, Pension Plan Characteristics and Framing Effects in Employee Savings Behavior, Review of Economics and Statistics 93, 228-243. 
Carroll, Christopher D., and Andrew A. Samwick, 1997, The Nature of Precautionary Wealth, Journal of Monetary Economics 40, 41-71.

Carroll, Gabriel D., James J. Choi, David Laibson, Brigitte C. Madrian, and Andrew Metrick, 2009, Optimal Defaults and Active Decisions, Quarterly Journal of Economics 124, $1639-1674$.

Chetty, Raj, John N. Friedman, Søren Leth-Petersen, Torben Heien Nielsen, and Tore Olsen, 2014, Active vs. Passive Decisions and Crowd-Out in Retirement Savings Accounts: Evidence from Denmark, Quarterly Journal of Economics 129, 1141-1219.

Choi, James, David Laibson, and Brigitte C. Madrian, 2009, Mental Accounting in Portfolio Choice: Evidence from a Flypaper Effect, American Economic Review 99, 2085-2099.

Choi, James J., David Laibson, and Brigitte C. Madrian, 2010, Why Does the Law of One Price Fail? An Experiment on Index Mutual Funds, Review of Financial Studies 23, $1405-1432$.

Choi, James J., David Laibson, Brigitte C. Madrian, and Andrew Metrick, 2003, Optimal Defaults, American Economic Review: Papers 83 Proceedings 93, 180-185.

Christelis, Dimitris, Dimitris Georgarakos, and Michael Haliassos, 2011, Stockholding: Participation, Location, and Spillovers, Journal of Banking and Finance 35, 1918-1930.

Cocco, João F., Francisco J. Gomes, and Pascal J. Maenhout, 2005, Consumption and Portfolio Choice over the Life Cycle, Review of Financial Studies 18, 491-533.

Cocco, João F., and Paula Lopes, 2011, Defined Benefit or Defined Contribution? A Study of Pension Choices, Journal of Risk and Insurance 78, 931-960.

Cronqvist, Henrik, and Richard H. Thaler, 2004, Design Choices in Privatized Social-Security Systems: Learning from the Swedish Experience, American Economic Review: Papers 83 Proceedings 94, 424-428.

Dahlquist, Magnus, José Vicente Martinez, and Paul Söderlind, 2016, Individual Investor Activity and Performance, forthcoming in Review of Financial Studies.

Dammon, Robert M., Chester C. Spatt, and Harold H. Zhang, 2004, Optimal Asset Location and Allocation with Taxable and Tax-Deferred Investing, Journal of Finance 59, 999-1037.

Epstein, Larry G., and Stanley E. Zin, 1989, Substitution, Risk Aversion, and the Temporal Behavior of Consumption and Asset Returns: A Theoretical Framework, Econometrica 57, 937-969.

Fagereng, Andreas, Charles Gottlieb, and Luigi Guiso, 2015, Asset Market Participation and Portfolio Choice over the Life-Cycle, forthcoming in Journal of Finance. 
Fischer, Marcel, Holger Kraft, and Claus Munk, 2013, Asset Allocation over the Life Cycle: How Much Do Taxes Matter?, Journal of Economic Dynamics 85 Control 37, 2217-2240.

French, Eric, and John Bailey Jones, 2011, The Effects of Health Insurance and SelfInsurance on Retirement Behavior, Econometrica 79, 693-732.

Gomes, Francisco, and Alexander Michaelides, 2005, Optimal Life-Cycle Asset Allocation: Understanding the Empirical Evidence, Journal of Finance 60, 869-904.

Gomes, Francisco, and Alexander Michaelides, 2008, Asset Pricing with Limited Risk Sharing and Heterogeneous Agents, Review of Financial Studies 21, 415-449.

Gomes, Francisco, Alexander Michaelides, and Valery Polkovnichenko, 2009, Optimal Savings with Taxable and Tax-Deferred Accounts, Review of Economic Dynamics 12, 718-735.

Gomes, Francisco J., Laurence J. Kotlikoff, and Luis M. Viceira, 2008, Optimal Life-Cycle Investing with Flexible Labor Supply: A Welfare Analysis of Life-Cycle Funds, American Economic Review: Papers \& Proceedings 98, 297-303.

Huberman, Gur, and Wei Jiang, 2006, Offering versus Choice in 401(k) Plans: Equity Exposure and Number of Funds, Journal of Finance 61, 763-801.

Judd, Kenneth L., Lilia Maliar, and Serguei Maliar, 2011, Numerically Stable and Accurate Stochastic Simulation Approaches for Solving Dynamic Economic Models, Quantitative Economics 2, 173-210.

Koijen, Ralph S.J., Stijn Van Nieuwerburgh, and Roine Vestman, 2015, Judging the Quality of Survey Data by Comparison with "Truth" as Measured by Administrative Records: Evidence from Sweden, Chapter in Improving the Measurement of Consumer Expenditures, edited by Christopher Carroll, Thomas Crossley, and John Sabelhaus. (University of Chicago Press).

Lucas, Deborah J., and Stephen P. Zeldes, 2009, How Should Public Pension Plans Invest?, American Economic Review: Papers $\& 5$ Proceedings 99, 527-532.

Lusardi, Annamaria, and Olivia S. Mitchell, 2014, The Economic Importance of Financial Literacy: Theory and Evidence, Journal of Economic Literature 52, 5-44.

Madrian, Brigitte C., and Dennis F. Shea, 2001, The Power of Suggestion: Inertia in 401(k) Participation and Savings Behavior, Quarterly Journal of Economics 116, 1149-1187.

Merton, Robert C., 1971, Optimal Consumption and Portfolio Rules in a Continuous-Time Model, Journal of Economic Theory 3, 373-413.

Michaelides, Alexander, and Yuxin Zhang, 2015, Stock Market Mean Reversion and Portfolio Choice over the Life Cycle, forthcoming in Journal of Financial and Quantitative Analysis. 
Poterba, James, Joshua Rauh, Steven Venti, and David Wise, 2007, Defined Contribution Plans, Defined Benefit Plans, and the Accumulation of Retirement Wealth, Journal of Public Economics 91, 2062-2086.

Poterba, James M., 2014, Retirement Security in an Aging Population, American Economic Review: Papers 83 Proceedings 104, 1-30.

Shiller, Robert J., 2006, Life-Cycle Personal Accounts Proposal for Social Security: An Evaluation of President Bush's Proposal, Journal of Policy Modeling 28, 427-444.

Sialm, Clemens, Laura T. Starks, and Hanjiang Zhang, 2015, Defined Contribution Pension Plans: Sticky or Discerning Money?, Journal of Finance 70, 805-838.

Vestman, Roine, 2015, Limited Stock Market Participation Among Renters and Home Owners, Working Paper.

Viceira, Luis M., 2001, Optimal Portfolio Choice for Long-Horizon Investors with Nontradable Labor Income, Journal of Finance 56, 433-470.

Vissing-Jørgensen, Annette, 2002, Towards an Explanation of Household Portfolio Choice Heterogeneity: Nonfinancial Income and Participation Cost Structures, Working Paper. 
Table 1: Averages of variables

\begin{tabular}{|c|c|c|c|}
\hline & All & Passive & Active \\
\hline \multicolumn{4}{|l|}{ Investors } \\
\hline Number of investors & 301,632 & 182,487 & 119,145 \\
\hline Fraction of investors & 1.000 & 0.605 & 0.395 \\
\hline \multicolumn{4}{|l|}{ State variables } \\
\hline Age & 46.8 & 46.6 & 47.0 \\
\hline Labor income & 248,420 & 224,526 & 285,017 \\
\hline Financial wealth & 248,039 & 217,846 & 294,284 \\
\hline \multicolumn{4}{|l|}{ Stock market exposure } \\
\hline Participation dummy & 0.520 & 0.455 & 0.619 \\
\hline Equity share (unconditional) & 0.234 & 0.196 & 0.290 \\
\hline Equity share (conditional) & 0.449 & 0.432 & 0.469 \\
\hline \multicolumn{4}{|c|}{ Real estate ownership and net worth } \\
\hline Real estate dummy & 0.708 & 0.652 & 0.793 \\
\hline Real estate wealth & 893,784 & 817,972 & $1,009,899$ \\
\hline Net worth & 737,760 & 665,790 & 847,993 \\
\hline \multicolumn{4}{|l|}{ Educational dummies } \\
\hline Elementary school & 0.157 & 0.184 & 0.116 \\
\hline High school & 0.544 & 0.539 & 0.551 \\
\hline College & 0.288 & 0.267 & 0.320 \\
\hline $\mathrm{PhD}$ & 0.011 & 0.010 & 0.013 \\
\hline
\end{tabular}

The table presents averages of variables for all investors and investor categories in 2007. At the end of 2007, the SEK/USD exchange rate was 6.47. "Passive" refers to investors who are invested in the default fund or who opted out of the default fund when entering the pension system but have since never changed their allocations. Out of the passive investors, 94,496 (or 51.8\%) are default investors. "Active" refers to investors who, after entering the pension system, made at least one change to their allocations. The number of investors refers to the number of investors in each category. The fraction of investors refers to the number of investors in each category relative to the total number of investors. Labor income refers to gross annual labor income. Financial wealth includes financial wealth outside the pension system, i.e., bank accounts, direct bond and stock holdings, mutual funds, as well as the balances in private pension accounts and capital insurance. The participation dummy is assigned a value of one if the investor holds either stocks or equity funds outside the pension system. The conditional equity share is for investors who participate in the stock market, where we assume that capital insurance accounts and private pension accounts include $60 \%$ equities and $40 \%$ bonds. The unconditional equity share is the value-weighted equity share over all investors. The real estate dummy is assigned a value of one if the investor owns either a house or an apartment. Real estate wealth is the value of houses and apartments (not conditioning on owning real estate). Net worth is the sum of financial wealth and real estate wealth minus total debt (e.g., mortgages, credit card debt, and student loans). The educational dummies are assigned a value of one for the investor's highest obtained education. 
Table 2: Activity and stock market participation

\begin{tabular}{|c|c|c|c|c|}
\hline & \multicolumn{2}{|c|}{ Activity dummy } & \multicolumn{2}{|c|}{ Participation dummy } \\
\hline & $\mathrm{I}$ & II & III & IV \\
\hline \multicolumn{5}{|l|}{ A. Main regressions } \\
\hline Age & $\begin{array}{l}0.038^{* * *} \\
(0.008)\end{array}$ & - & $\begin{array}{l}0.220^{* * *} \\
(0.008)\end{array}$ & - \\
\hline Labor income & $\begin{array}{l}0.216^{* * *} \\
(0.004)\end{array}$ & - & $\begin{array}{l}0.173^{* * *} \\
(0.004)\end{array}$ & - \\
\hline Financial wealth & $\begin{array}{l}0.049^{* * *} \\
(0.002)\end{array}$ & - & $\begin{array}{l}0.281^{* * *} \\
(0.002)\end{array}$ & - \\
\hline Real estate dummy & $\begin{array}{l}0.122^{* * *} \\
(0.002)\end{array}$ & $\begin{array}{l}0.068^{* * *} \\
(0.002)\end{array}$ & $\begin{array}{l}0.167^{* * *} \\
(0.002)\end{array}$ & $\begin{array}{l}0.074^{* * *} \\
(0.002)\end{array}$ \\
\hline Educational dummies & Yes & Yes & Yes & Yes \\
\hline Geographical dummies & Yes & Yes & Yes & Yes \\
\hline Age/income/wealth splines & No & Yes & No & Yes \\
\hline$R$-squared & 0.044 & 0.067 & 0.150 & 0.291 \\
\hline Number of observations & 301,632 & 301,632 & 301,632 & 301,632 \\
\hline \multicolumn{5}{|l|}{ B. Residual regressions } \\
\hline Activity & & & $\begin{array}{l}0.101^{* * *} \\
(0.002)\end{array}$ & $\begin{array}{l}0.060^{* * *} \\
(0.002)\end{array}$ \\
\hline$R$-squared & & & 0.011 & 0.005 \\
\hline Number of observations & & & 301,632 & 301,632 \\
\hline
\end{tabular}

Panel A presents the results of regressions of activity and stock market participation on various variables. Specifications I and II regress an activity dummy (one if the investor is active in the pension system, zero otherwise) on the variables; Specifications III and IV regress a participation dummy (one if the investor participates in the stock market, zero otherwise) on the variables. Specifications I and III use the state variables of a life-cycle portfolio choice model (i.e., age, labor income, and financial wealth) and a dummy for real estate ownership as regression variables. Age is scaled down by 100, and labor income and financial wealth are scaled down by 1,000,000. All specifications include educational and geographical dummy variables. Specifications II and IV replace the linear specifications of age, labor income, and financial wealth with piecewise linear splines. For brevity, the coefficients of these variables are not presented in the table. Panel B presents the results of regressions of the residuals from the participation regressions (Specifications III and IV) on the residuals from the activity regressions (Specifications I and II). The sample consists of investors in 2007. At the end of 2007, the SEK/USD exchange rate was 6.47. Standard errors, robust to conditional heteroscedasticity, are reported in parentheses. ${ }^{*}, * *$, and ${ }^{* * *}$ denote significance at the $10 \%, 5 \%$, and $1 \%$ level, respectively. 
Table 3: Distribution of variables for passive investors

\begin{tabular}{llllll}
\hline \hline & & & & & \\
& & & & & \\
\end{tabular}

A. All passive investors

Age

Labor income

Financial wealth

Equity share

$30 \quad 38$

46

56

64

46.6

$\begin{array}{rrr}0 & 99,911 & 225,373 \\ 7,135 & 17,116 & 68,580\end{array}$

$303,797 \quad 401,252$

224,526

217,846

$\begin{array}{lll}0.000 & 0.000 & 0.000\end{array}$

0.401

560,981

0.196

\section{B. Participants}

Age

Labor income

Financial wealth

Equity share

$\begin{array}{rrrrrr}32 & 39 & 48 & 58 & 65 & 48.3 \\ 0 & 137,245 & 250,315 & 336,004 & 460,812 & 258,714 \\ 26,272 & 68,468 & 176,367 & 432,910 & 934,804 & 374,888 \\ 0.088 & 0.234 & 0.438 & 0.609 & 0.764 & 0.432\end{array}$

\section{Non-participants}

Age

$\begin{array}{rrrrrr}30 & 36 & 44 & 54 & 62 & 45.2 \\ 0 & 72,964 & 205,647 & 277,920 & 350,952 & 195,969 \\ 7,135 & 7,135 & 26,996 & 83,589 & 207,063 & 86,676 \\ 0.000 & 0.000 & 0.000 & 0.000 & 0.000 & 0.000\end{array}$

The table presents the averages of variables for passive investors by percentiles in 2007. At the end of 2007, the SEK/USD exchange rate was 6.47. Panel A refers to all passive investors. Panel B refers to passive investors who participate in the stock market. Panel C refers to passive investors who do not participate in the stock market. Labor income refers to gross annual labor income. A total of 182,487 investors are represented in Panel A, 83,053 in Panel B, and 99,434 in Panel C. Financial wealth includes financial wealth outside the pension system, i.e., bank accounts, direct bond and stock holdings, mutual funds, as well as the balances in private pension accounts and capital insurance. Missing bank account balances have been imputed to SEK 7,135. The equity share in Panel B is for investors who participate in the stock market, where we assume that capital insurance accounts and private pension accounts include $60 \%$ equities and $40 \%$ bonds; the equity share in Panel $\mathrm{C}$ is that of investors who do not participate in the stock market and by definition equals zero. 
Table 4: Model parameters

\begin{tabular}{|c|c|c|}
\hline & Notation & Value \\
\hline \multicolumn{3}{|l|}{$\underline{\text { Returns }}$} \\
\hline Gross risk-free rate & $R_{f}$ & 1.00 \\
\hline Equity premium & $\mu$ & 0.04 \\
\hline Standard deviation of stock market return & $\sigma_{\varepsilon}$ & 0.18 \\
\hline \multicolumn{3}{|l|}{ Labor income and financial wealth } \\
\hline Standard deviation of idiosyncratic labor income shock & $\sigma_{\eta}$ & 0.072 \\
\hline Weight of stock market shock in labor income & $\theta$ & 0.040 \\
\hline Standard deviation of initial labor income & $\sigma_{z}$ & 0.366 \\
\hline Standard deviation of initial financial wealth & $\sigma_{A}$ & 1.392 \\
\hline Mean of initial financial wealth & & 76,800 \\
\hline \multicolumn{3}{|l|}{ Contribution rates in pension accounts } \\
\hline $\mathrm{DC}$ account & $\lambda^{\mathrm{DC}}$ & $7 \%$ \\
\hline Notional account & $\lambda^{\mathrm{N}}$ & $16 \%$ \\
\hline \multicolumn{3}{|l|}{ Life-cycle profiles } \\
\hline Labor-income profile & $g_{t}$ & - \\
\hline Survival rates & $\phi_{t}$ & - \\
\hline \multicolumn{3}{|l|}{ Preferences and stock market participation cost } \\
\hline Elasticity of intertemporal substitution & $1 / \rho$ & 0.500 \\
\hline Discount factor* & $\beta$ & 0.933 \\
\hline Relative risk aversion* & $\gamma$ & 14 \\
\hline Ceiling for opt-out cost* & $\bar{\kappa}^{\mathrm{DC}}$ & 3,600 \\
\hline Ceiling for stock market entry cost* & $\bar{\kappa}$ & 15,600 \\
\hline Number of layers in the cost distribution* & & 3 \\
\hline
\end{tabular}

The table presents the parameter values of the model. $*$ The parameter value has been determined endogenously by simulation of the model. The labor-income profiles are discussed in detail in the main text. The survival rates are computed from unisex statistics provided by Statistics Sweden. At the end of 2007, the SEK/USD exchange rate was 6.47. 
Table 5: Matched moments in the data and model

\begin{tabular}{lcc}
\hline \hline & Data & Model \\
& & \\
\hline & & \\
Financial wealth to labor income ratio & 0.922 & 0.921 \\
& & \\
Equity share (conditional) & 0.454 & 0.519 \\
& & \\
Active (opting out) / non-participation & 0.151 & 0.158 \\
Active (opting out) / participation & 0.244 & 0.255 \\
Passive (default) / non-participation & 0.330 & 0.316 \\
Passive (default) / participation & 0.275 & 0.271 \\
& & \\
& &
\end{tabular}

The table presents matched moments in the data and model. We consider data from the working phase. Activity in the data corresponds to opting out in the model. The table implies that the share of passive (default) investors is $0.605(0.330+0.275)$ in the data and $0.587(0.316+0.271)$ in the model; the share of non-participating investors is $0.481(0.151+0.330)$ in the data and $0.474(0.158+0.316)$ in the model. 


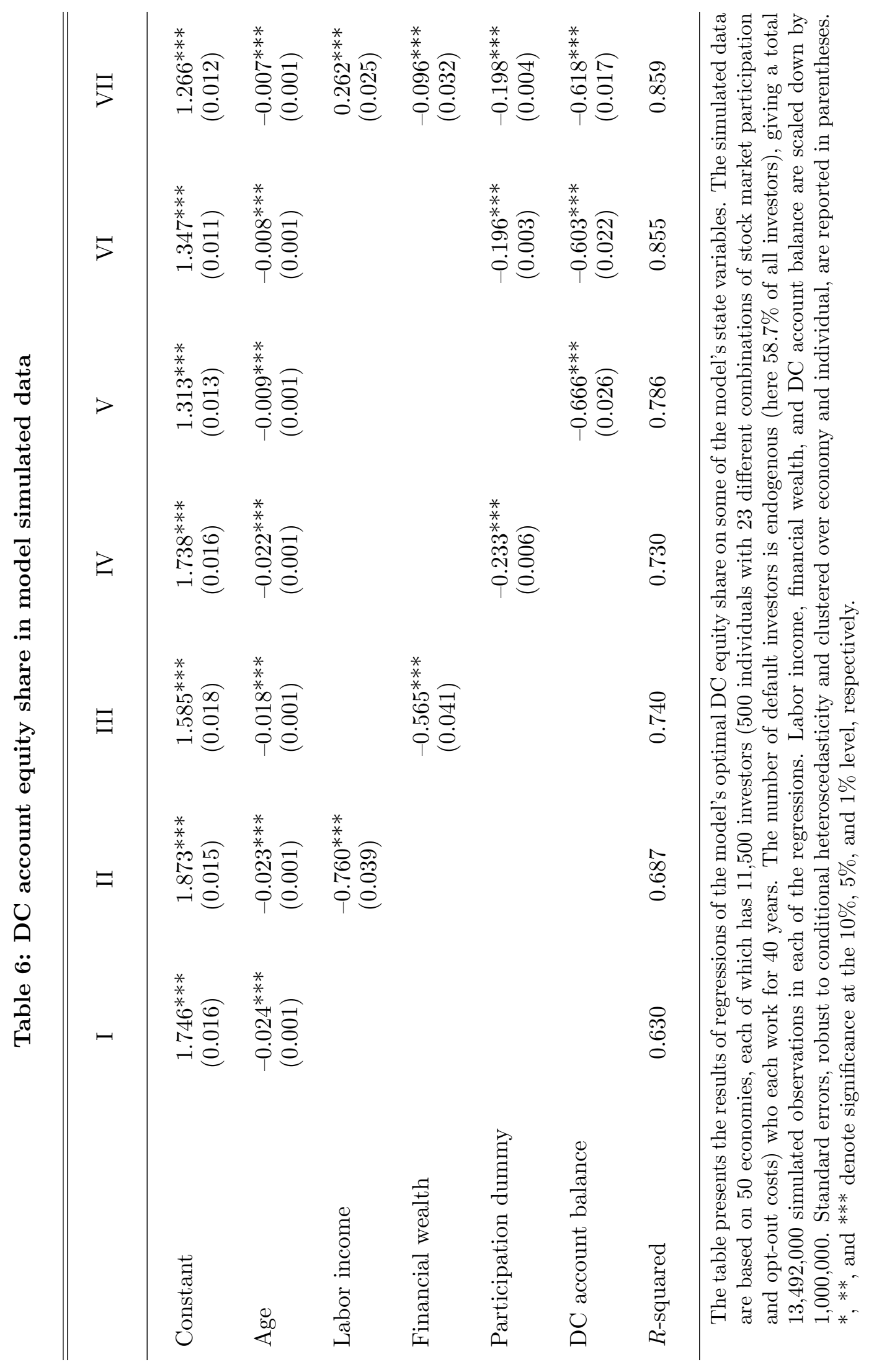


Table 7: Welfare analysis and endogenously determined default investors

\begin{tabular}{|c|c|c|c|c|}
\hline & "100-minus-age" & Average optimal & Rule of thumb & Optimal \\
\hline Share of default investors & 0.587 & 0.679 & 0.753 & 1.000 \\
\hline Incremental welfare gain & - & $0.3 \%$ & $0.6 \%$ & $0.6 \%$ \\
\hline Cumulated welfare gain & - & $0.3 \%$ & $0.9 \%$ & $1.5 \%$ \\
\hline \multicolumn{5}{|l|}{$\underline{\text { Regressions }}$} \\
\hline Constant & $\begin{array}{l}1.347^{* * *} \\
(0.011)\end{array}$ & $\begin{array}{l}1.363^{* * *} \\
(0.015)\end{array}$ & $\begin{array}{l}1.384^{* * *} \\
(0.018)\end{array}$ & $\begin{array}{l}1.411^{* * *} \\
(0.022)\end{array}$ \\
\hline Age & $\begin{array}{l}-0.008^{* * *} \\
(0.001)\end{array}$ & $\begin{array}{l}-0.009^{* * *} \\
(0.001)\end{array}$ & $\begin{array}{l}-0.009^{* * *} \\
(0.001)\end{array}$ & $\begin{array}{l}-0.010^{* * *} \\
(0.001)\end{array}$ \\
\hline Participation dummy & $\begin{array}{l}-0.196^{* * *} \\
(0.003)\end{array}$ & $\begin{array}{l}-0.199^{* * *} \\
(0.003)\end{array}$ & $\begin{array}{l}-0.198^{* * *} \\
(0.003)\end{array}$ & $\begin{array}{l}-0.195^{* * *} \\
(0.003)\end{array}$ \\
\hline DC account balance & $\begin{array}{l}-0.603^{* * *} \\
(0.022)\end{array}$ & $\begin{array}{l}-0.564^{* * *} \\
(0.027)\end{array}$ & $\begin{array}{l}-0.533^{* * *} \\
(0.031)\end{array}$ & $\begin{array}{c}-0.505^{* * *} \\
(0.035)\end{array}$ \\
\hline$R$-squared & 0.855 & 0.855 & 0.853 & 0.850 \\
\hline \multicolumn{5}{|l|}{$\underline{\text { Pension income }}$} \\
\hline Mean & 154,880 & 155,461 & 158,952 & 152,281 \\
\hline Equity risk & 0.121 & 0.122 & 0.127 & 0.087 \\
\hline Inequality & 0.234 & 0.233 & 0.194 & 0.196 \\
\hline
\end{tabular}

The table presents the effects of a gradual implementation of a more customized default fund. The first column indicates the initial design, "100-minus-age." The fourth column indicates implementation of the model's optimal (fully customized) default allocation. The second and third column are intermediary allocations steps (average optimal and rule-of-thumb allocations). The first line reports the share of default investors out of a total population default and opt-out investors equal to 11,500. The second line reports the incremental welfare gain in percent during the retirement phase of moving one step towards more customization from the first column. The third line reports the cumulative gain in percent. The regressions report regression as in Table 6 for the group of default investors generated under the respective default design. The first column is identical to column VI of Table 6. The simulated data are based on 50 economies, each of which has 11,500 investors who each work for 40 years. The number of default investors in each column are as follows: $13,492,000 ; 15,624,000 ; 17,326,000$ and 23,000,000. Labor income, financial wealth, and DC account balance are scaled down by 1,000,000. Standard errors, robust to conditional heteroscedasticity and clustered over economy and individual, are reported in parentheses. ${ }^{*},{ }^{* *}$, and $* * *$ denote significance at the $10 \%, 5 \%$, and $1 \%$ level, respectively. Pension income refers to pension income at 65 . For pension income, the sample in all columns is held constant to the default investors under "100-minus-age" (6,746 individuals). The mean refers to the average over economies and individuals. Equity risk is the standard deviation of the log of average pension income across 50 economies. Inequality is the standard deviation of the log of average pension income across 6,746 individuals. 
Figure 1: Calibration and model fit
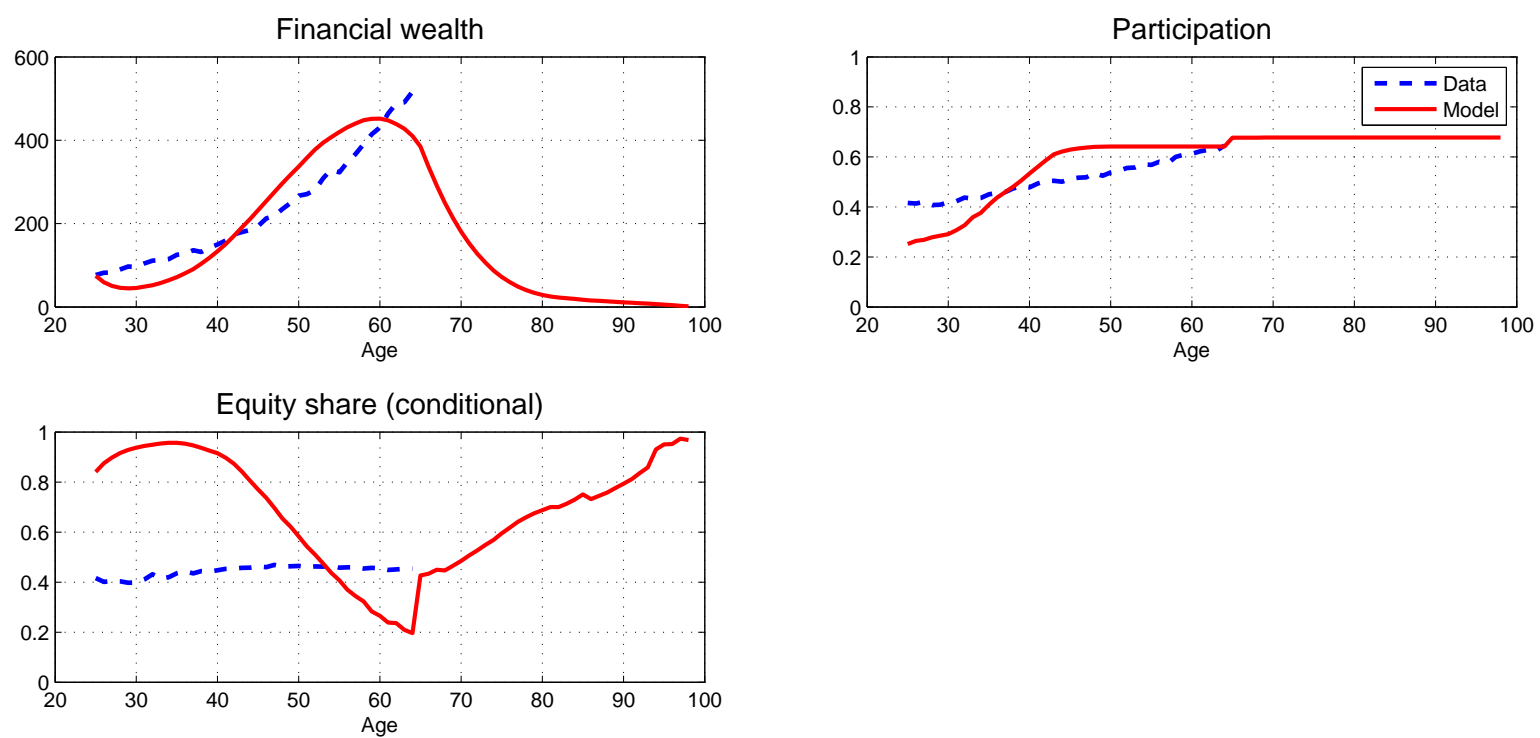

The figure shows the fit of the model relative to data. The model simulation is based on 50 economies and 11,500 individuals. Financial wealth is expressed in SEK 1000s. 


\section{Figure 2: Model fit of participants/non-participants and default/opt-out investors}
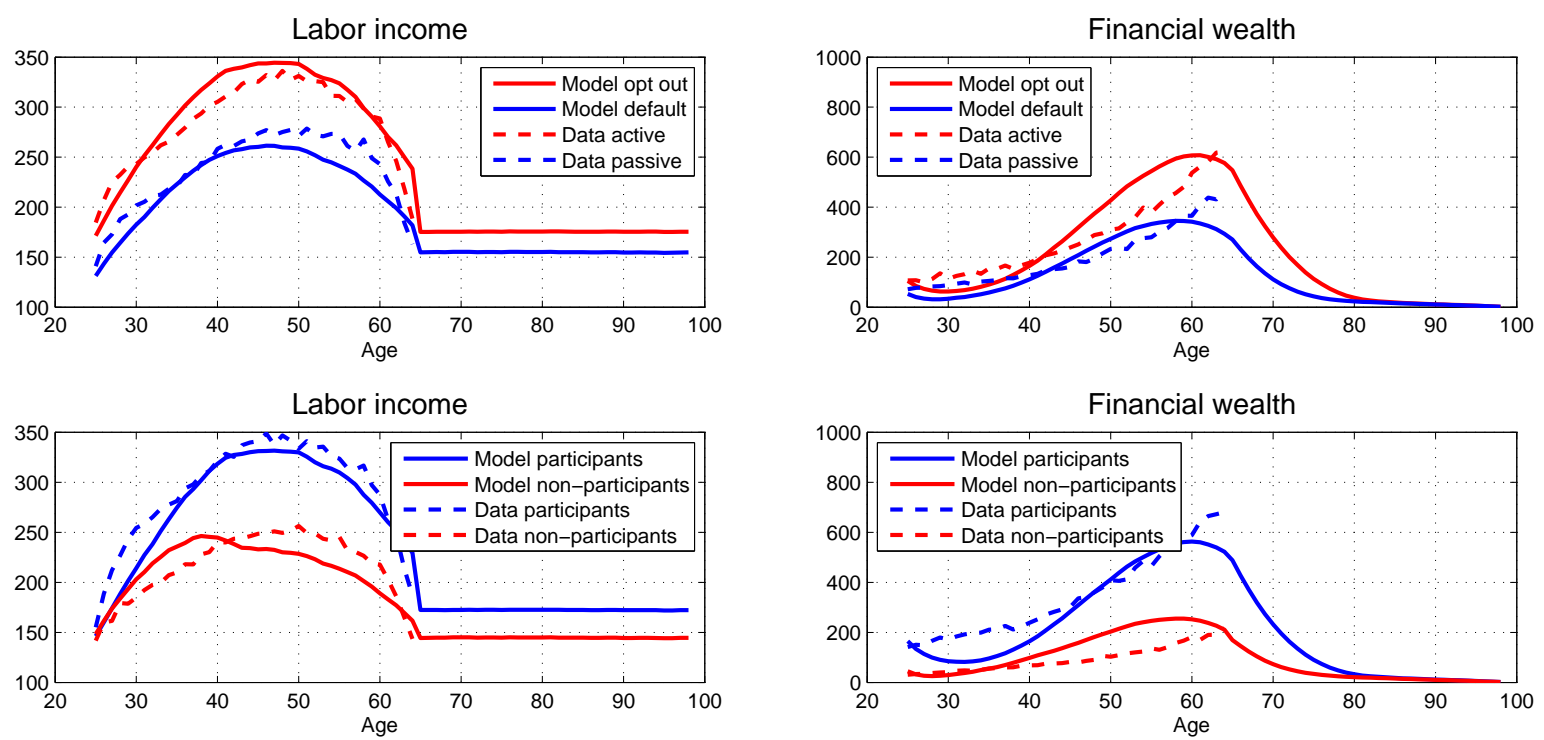

The figure shows the average labor income and financial wealth (both in SEK 1000s) for default/opt-out and participants/non-participants investors due to endogenous sorting. 
Figure 3: Averages for default and opt-out investors
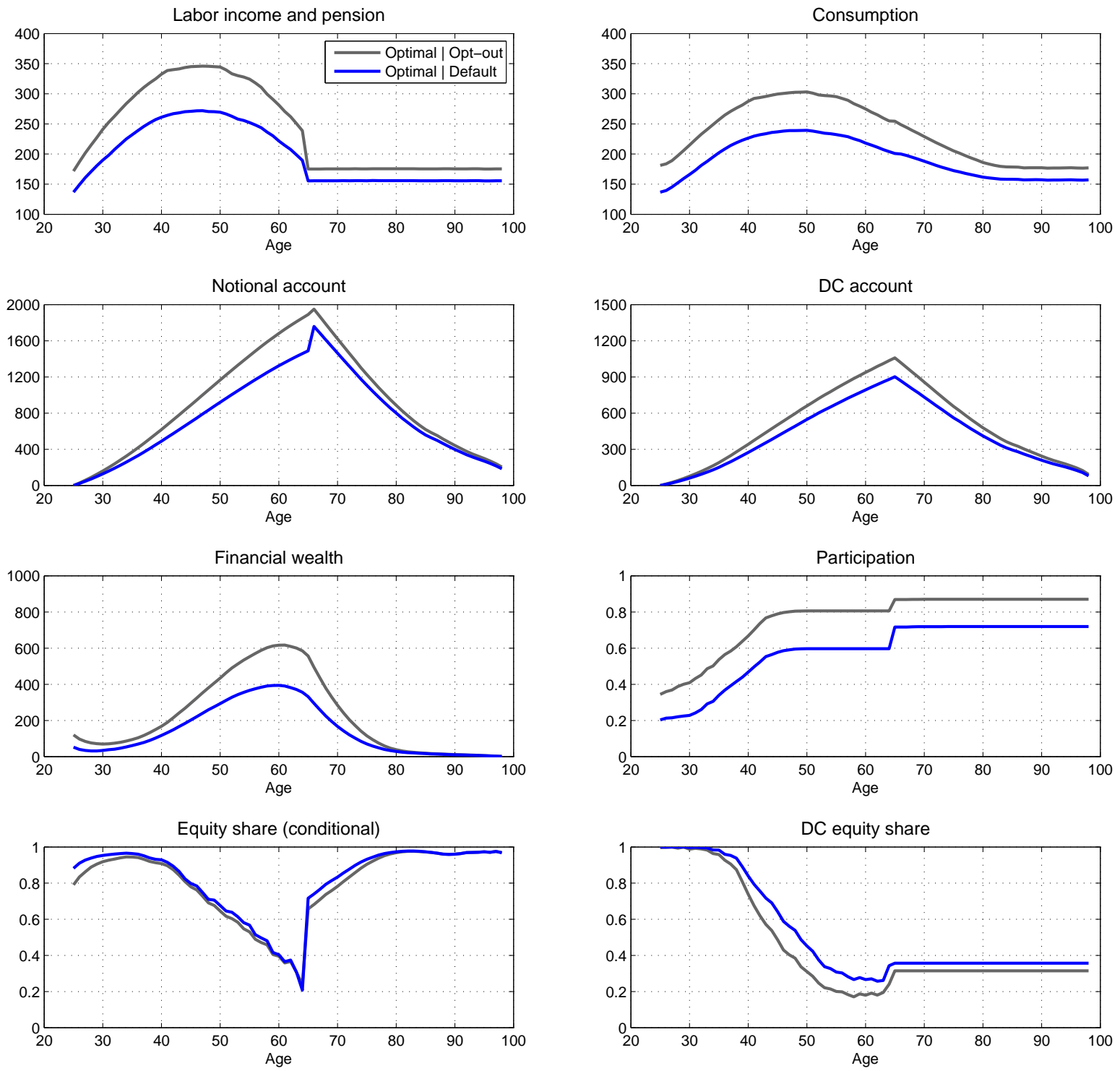

The figure shows averages over 50 economies and 11,500 individuals for the optimal asset allocation of opt-out and default investors (4,754 versus 6,746 individuals). The endogenous separation between the two groups was generated under a DC equity share equal to "100-minus-age" (as in the calibration). Labor income and pension, consumption, notional and DC accounts, and financial wealth are expressed in SEK 1000s. 
Figure 4: Aggregate equity risk and inequality implied by the optimal asset allocation


The figure shows the aggregate equity risk and inequality for the optimal asset allocation of default investors. The simulation is based on 50 economies and 11,500 individuals. The left panels show how the averages vary over 50 economies. The second decile refers to the average of economies 6-10 (sorted). The ninth decile refers to the average of economies 41-45 (sorted). The right panels show how the averages vary over individuals who endogenously become default investors. A decile is then $1 / 10$ of these default investors. Note that the same economies and individuals are not tracked over time, i.e., the sorting at one age is independent of the sorting at another age. The DC account, labor income and pension, and financial wealth are expressed in SEK 1000s. 